\title{
The Dynamics of Security Trades, Quote Revisions, and Market Depths for Actively Traded Stocks
}

\author{
Shafiqur Rahman* \\ Professor of Banking and Finance \\ School of Business Administration \\ Portland State University \\ Portland, Oregon \\ Chandrasekhar Krishnamurti \\ Associate Professor of Banking and Finance \\ Nanyang Business School \\ Nanyang Tech University \\ Singapore
}

Alice C. Lee

Assistant Professor of Finance

College of Business

San Francisco State University

San Francisco, California

January 2005

JEL Classification: C32; D82; G10

Keywords: Intra-day Dynamics; Depth; Volatility; Trading Activity; Vector Auto- Regression

* Please send correspondences to: Professor Shafiqur Rahman, School of Business Administration, Portland State University, P. O. Box 751, Portland, OR 97207-0751, USA. 503.725 .3715 (Voice), 503.725.5850 (Fax), Email: hesr@pdx.edu. 


\title{
The Dynamics of Security Trades, Quote Revisions, and Market Depths for Actively Traded Stocks
}

\begin{abstract}
We examine the dynamics of return volatility, trading volume and depth - in an intraday setting for a sample of actively traded NYSE and NASDAQ stocks. We show that depth is a useful intervening variable and mitigates the impact of trading activity on price volatility. Furthermore, depth is affected by the perception of prevailing information asymmetry between informed and uninformed traders. We demonstrate empirically that NYSE supplies greater depth under conditions of high, perceived information asymmetry as compared to NASDAQ. NASDAQ makes up for this deficiency by its capability of managing large volume shocks without a major decline in depth.
\end{abstract}




\section{The Dynamics of Security Trades, Quote Revisions, and Market Depths for Actively Traded Stocks}

\section{Introduction}

The association between trading activity and price volatility has been the subject of much research attention. ${ }^{1}$ Trades are commonly dichotomized into liquidity-driven and information-driven transactions. While liquidity-driven trades are a source of trading friction resulting in transitory price changes, information-driven trades convey information to other traders and result in permanent changes in stock prices. Thus the familiar Wall Street adage "it takes volume to move prices". 2 Other papers infer causality to run in the reverse direction from price volatility to trading activity owing to dealer inventory control behavior. ${ }^{3}$

Recent work has added a third dimension to this research by including depth. ${ }^{4}$ Depth represents the proclivity of uninformed traders to supply liquidity. It is a useful intervening variable since it has the potential to mitigate the impact of trading activity on price volatility. ${ }^{5}$ The provision of depth is affected by the perception of prevailing information asymmetry between informed and uninformed traders. An increase in trading activity causes depth to increase when trades are presumed to be noninformational. On the other hand, trades believed to be information-driven exacerbate the perceived information asymmetry and cause a reduction in depth. ${ }^{6}$ In a similar vein, information-driven price volatility changes result in depth reduction while non-

\footnotetext{
1 See for instance Admati and Pfleiderer (1988).

2 Karpoff (1987) offers a survey based on the early literature in this area.

3 Ho and Stoll (1983) typify this particular aspect of dealer's quote behavior.

4 Lee, Mucklow and Ready (1993) were one of the first to examine this issue empirically. There has been a recent proliferation of work involving depth.

${ }^{5}$ Bessembinder and Seguin (1993) provide confirmatory empirical evidence from futures markets regarding this phenomenon.

${ }^{6}$ See Lee, Mucklow and Ready (1993).
} 
informational changes result in an increase in depth. ${ }^{7}$ In a nutshell, we have strong justification to expect bi-directional causality between the three variables of interest: trading activity, price volatility, and quoted depth. To our surprise, extant research has not yet incorporated all the interactions including the feedback effects involving volume, volatility and depth in studies concerning U.S. equity markets. ${ }^{8}$ Our study rectifies this lacuna.

We outline below our contribution to the literature. First, we examine the joint dynamics affecting trade-quote-depth in U.S. stock markets. Prior literature has largely focussed on probing only two variables at a time. We believe that we will gain additional insights by a joint investigation involving all three variables. A second contribution pertains to our attempt to develop predictions regarding the direction of impact of each predictor variable on the dependent variables. Furthermore, we classify the direction of impact depending on whether the change in predictor variable is driven by information or not. We find that our scheme provides a set of testable implications of the dynamics of the three variables of interest. Interestingly, there arise certain ambiguities in our theoretical predictions. The first ambiguity concerns the impact of quote revisions on trades. The informational effect of a quote revision on trades is expected to be positive, while the non-informational effect is predicted to be negative. The net effect is uncertain. The net impact of trades on depth represents our second ambiguity. The informational impact is considered to be negative while the non-informational impact is expected to be positive. Finally the impact of quote revision on depth is also indeterminate as the informational impact is likely to

\footnotetext{
${ }^{7}$ Ahn, Bae and Chan (2001) show that a rise in volatility is followed by an increase in market depth on the Hong Kong Stock Exchange. They do not address the issue of whether information-driven volatility impacts depth differently as compared to a non-informational increase in volatility.

8 Ahn, Bae and Chan (2001) provide some insights regarding the trade-quote-depth dynamics using data from Hong Kong Stock Exchange. Fung and Patterson (1999) examine currency futures markets to understand the trade-quote-depth dynamics.
} 
negative while the non-informational impact is predicted to be positive. We conduct empirical tests using transaction data from NYSE and NASDAQ to resolve these ambiguities.

Empirical results show that the net impact of quote revisions on trades is positive in both NYSE and NASDAQ stocks indicating that the informational effect dominates the non-informational effects such as inventory control. The net impact of trades on depth is negative on the NYSE, but positive on NASDAQ. Finally, the net impact of quote revisions on depth is positive on NYSE while it is negative on NASDAQ. Apparently, NYSE copes better with volatility shocks and provides a more liquid market as evidenced by greater depth.

As a third contribution, we investigate whether market structure has an effect on the observed trade-quote-depth dynamics. We show empirically that NYSE provides better depth under situations of high, perceived information asymmetry as compared to NASDAQ. ${ }^{9}$ NASDAQ compensates for this inadequacy by its capacity to handle large volume shocks without a significant deterioration in depth. As a final contribution, we address the issue of whether liquidity providers dynamically alter their strategies in response to changing conditions of information asymmetry. In particular, we determine whether they supply less liquidity fearing consequences of adverse selection during periods of high information asymmetry and augment the supply at other times.

We organize the rest of the paper as follows. In the next section, we outline related research and motivate our methodology. In section III, we describe our data and report empirical results. In the final section, we offer our concluding remarks.

\footnotetext{
${ }^{9}$ Huang and Stoll (1996) provide evidence on superiority of NYSE using a set of liquidity variables.
} 


\section{Related Research and Methodology}

A. Review of Prior Literature

In this section, we briefly review prior research in order to motivate our work. Price volatility has been the subject of a number of papers in market microstructure. According to Madhavan, Richardson and Roomans (1997) security prices change in response to information flows and trading frictions. Furthermore, researchers have documented a contemporaneous association between trades and price volatility. ${ }^{10}$ The motivation for transactions is commonly dichotomized into information-driven and liquidity-driven trades. In market microstructure theory, liquidity-driven trades are a source of trading frictions and are associated with transitory price changes. These price changes eventually reverse themselves. On the other hand, information-driven trades are associated with permanent changes in stock prices. This finding lends credence to the view that the process of trading results in information transfer from the privately informed to the market maker. In short, the presumed causality runs from trading activity to price volatility due to the information content of trades. We portray this in Figure 1, which provides a comprehensive picture of the direction of association between the predictor variables and the dependent variables. We use quote revision (Q) as our measure of price volatility, net buy volume as our proxy for trading activity (T), and net depth (D) to assess the quantity of depth. As we can see from the figure, trades are expected to positively impact quote volatility due to the predicted positive impact of both the informational and non-informational effects.

$$
=====\text { Insert Figure } 1 \text { about here }=====
$$

Other papers offer compelling grounds to expect causality to run in the reverse direction, viz., from price volatility to trading activity, the principal motivation being

\footnotetext{
${ }^{10}$ See for instance Admati and Pfleiderer (1988).
} 
the inventory control behavior of market makers. Ho and Stoll (1983) and Stoll (1976), contain theoretical arguments and empirical evidence supporting the view that dealers use quote revisions as an inventory control mechanism. When dealers suffer from an imbalance of excess buy or sell orders, they revise quotes to elicit the opposite response in order to maintain the inventory at an optimal level. When inventory is greater (less) than desired, quotes are lowered (raised) to motivate sales (purchases). Thus we predict that the non-informational quote revision effect (mainly inventory control) on future trades should be negative. Quote revision could also occur due to informational reasons. An informational quote revision effect is expected to positively influence trades. This can happen if some traders believe that prices have not fully adjusted to any new information that has just been disseminated. The net impact of the informational and non-informational effects of quote revisions on trades is therefore ambiguous and depends on the relative strengths of the two effects. This is represented under the Q T column shown in Figure 1.

While the relationship between trades and quotes has been examined in the literature, market depth has been left out by most of the studies, even though depth may be fundamentally related to trading activity and quote movements [Lee, Mucklow, and Ready (1993) and Bessembinder and Seguin (1992, 1993)]. Lee, Mucklow, and Ready (1993) point out those providers of liquidity are sensitive to changes in information asymmetry risk and use both spreads and depths in actively managing this risk. A recent study by Fung and Patterson (1999) incorporates market depth in their examination of the dynamic relationships between volume and volatility in currency futures markets. In deeper markets, trading volume shocks are expected to have a smaller impact on volatility as compared to shallower markets. Bessembinder and Seguin (1993) provide confirmatory empirical evidence from 
agricultural and financial futures markets. They document a negative relationship between their proxy for depth and price volatility. Accordingly, we predict the impact of depth on quote volatility to be negative and record it in figure 1. Since depth providers are on the passive side of the market, the impact of depth is considered largely non-informational. According to Kyle (1985) depth represents the proclivity of uninformed traders to supply liquidity. An increase in market depth is thus expected to mitigate the impact of a volume shock on volatility. Furthermore, he asserts that market depth is adversely affected by information asymmetry existing between privately informed traders and uniformed traders. Thus it is logical to argue that depth providers supply less liquidity when they perceive an exacerbation in information asymmetry.

Liquidity providers may be observing trading activities and price movements in determining whether there has been a rise in information asymmetry. If in their judgement, the increase in trades is caused by informational trading, then they supply less depth. On the other hand, an increase in trading activity due to non-informational reasons should lead to a higher depth. We thus expect the informational impact of trade on depth to be negative whereas the non-informational effect is predicted to be positive. The net effect is therefore ambiguous and depends on the comparative strengths of the informational and non-informational effects. In a similar manner, liquidity providers observe price volatility and make assessments regarding information asymmetry. If they believe that price movements are driven by privately informed traders, then they supply less depth. Otherwise they provide more depth. Thus we have an indefinite prediction for the impact of price volatility on depth. We clearly record these ambiguities in Figure 1. Therefore, we are constrained to rely on empirical procedures to resolve these ambiguities. Finally, depth is expected to have a 
direct impact on trading activity. Traders find it easier to transact large volumes in a stock that has higher depth. In a nutshell, we have strong priors to expect bidirectional causality between price volatility and trading volume, depth and price volatility, and depth and trading volume. Surprisingly, extant research does not yet contain a study that incorporates all the interactions, including feedback effects, between the three variables: volume, price volatility and depth in the U.S. equity markets. ${ }^{11}$ Our study remedies this significant lacuna.

Several recent papers include depth as one of the measures of liquidity. While most of these studies use quoted depth at $\mathrm{BBO}$ as a measure of liquidity some use limit order depth to describe displayed liquidity. We follow the example of Kumar, Sarin and Shastri (1998), Jones and Lipson (2001), Chung, Van Ness, and Van Ness (2002), and Chung and Chuwonganant (2001) in examining displayed liquidity. Studies that use limit order depth to characterize liquidity include the work of Chung, Van Ness, and Van Ness (2001a), Goldstein and Kavajecz (2000), and Kavajecz (1999). We choose to use quoted depth at the BBO to proxy for displayed liquidity rather than limit order depth. While limit order depth is preferable on the grounds that it provides a complete picture, the principal disadvantage is that it is not accessible to most researchers.

\section{B. Methodology}

We model the dynamic relationship involving trades, price volatility, and depth using a trivariate vector autoregressive system. Our VAR system can be expressed as follows:

$$
r_{t}=\sum_{i=1}^{p} a_{i} r_{t-i}+\sum_{i=0}^{p} b_{i} x_{t-i}+\sum_{i=1}^{p} c_{i} z_{t-i}+\varepsilon_{t}
$$

\footnotetext{
${ }^{11}$ Ahn, Bae and Chan (2001) examine the relation between volatility and market depth on the Hong Kong stock exchange. They show that rise in volatility is followed by an increase in market depth. They also find that an increase is market depth is followed by a decrease in volatility.
} 


$$
\begin{aligned}
& x_{t}=\sum_{i=1}^{p} d_{i} x_{t-i}+\sum_{i=1}^{p} e_{i} r_{t-i}+\sum_{i=1}^{p} f_{i} z_{t-i}+\eta_{t} \\
& z_{t}=\sum_{i=1}^{p} g_{i} z_{t-i}+\sum_{i=1}^{p} h_{i} r_{t-i}+\sum_{i=1}^{p} k_{i} x_{t-i}+\varphi_{t}
\end{aligned}
$$

where $r_{t}$ is the quote-return, $x_{t}$ is the net-buy volume, and $z_{t}$ is the net-depth at time $\mathrm{t}$. It is customary in market microstructure literature to distinguish between buyerinitiated and seller-initiated trades. ${ }^{12}$ Market makers infer order imbalances by comparing buyer initiated trades with seller-initiated trades. Thus net-buy volume rather than total trading volume is expected to affect price volatility. We expect a significant increase (decrease) in net-buy volume to push the bid and ask quotes upward (downward). Thus we measure quote returns using the mid-point of bid and ask quotes as our proxy of price volatility. Furthermore, for the sake of consistency, we use net-depth, the difference between the size of the ask quote and bid quote, in our empirical tests.

We use two approaches of Chan and Fong (2000) to determine whether a trade is buyer-initiated or seller-initiated. In the first approach, following Lee and Ready (1991), we compare the transaction price with the prevailing bid-ask quotes. The trade is classified as buyer- (seller-) initiated if the trade takes place at the ask (bid) price. If the trade takes place at the price that lies between the bid and ask, we follow Harris (1989) and record the trade as buyer- (seller-) initiated if the transaction price is closer to the ask (bid). In the second approach, which we use only if we cannot determine the direction of a trade using the first approach, we employ tick test to compare the current transaction price with the preceding transaction price(s). A trade is classified as buyer- (seller-) initiated if it takes place on an up tick (downtick) or a zero up tick (downtick). When trades takes place on consecutive zero ticks, it is not classified.

\footnotetext{
${ }^{12}$ See for instance, Chan and Fong (2000).
} 
Microstructure imperfections may cause lagged effects. Price discreteness, for example, may induce threshold effects, since a quote revision may not be optimal until a sequence of trades of the same direction has taken place. Inventory control considerations, lagged adjustment to information, and price smoothing may also induce serial correlation in quote return. These considerations justify inclusion of current and lagged values of net-buy volume as well as lagged quote return in equation (1). Equation (1) is robust enough to allow the quote-return to be affected by public information (e.g., news announcement), private information (e.g., informed traders submitting limit orders) and several microstructure effects such as institutional restriction in the form of price discreteness, inventory control effects, lagged adjustment to information, price pressure, order fragmentation, and exchangemandated price smoothing [Hasbrouck (1991) and Chan, Chung, and Fong (2002)]. It is assumed that the disturbances in the three equations have zero means and are jointly and serially uncorrelated. The above system is very similar to the usual VAR specification except that the contemporaneous volume shows up as one of the explanatory variables in equation (1). Therefore, while $x_{t}$ could influence contemporaneous and future values of $r_{t}, r_{t}$ could only affect future values of $x_{t}$. In other words, there is a presumption of causality running from both contemporaneous and lagged trades to quote revisions, but from only lagged quote revisions to trades [Hasbrouck (1991)]. Likewise, net-buy volume in equation (2) is a function of its own lagged values and lagged values of quote return and net-depth because of market microstructure induced serial correlation. Moreover, Hasbrouck (1991) pointed out that based on knowledge of the trade and price history, agents use equation (2) to form an expectation of the trade. Equation (3) captures impact of own lagged values and lagged values of quote-return and net-buy volume on net-depth. These three 
equations together examine the interaction of quote return, net-buy volume, and netdepth in an intraday setting.

Prior research papers on the price-trading activity dynamics have used various time intervals for measuring the variables of interest. Hasbrouck (1991) uses a transaction by transaction approach in his work. Chan and Fong (2000) use daily intervals in their study of NYSE and NASDAQ stocks. Ahn, Bae and Chan (2001) use a 15-minute interval in their study of the Hong Kong stock market. We utilize the findings of Dufour and Engle (2000) who find that the price of IBM stock converges to the full information level in about four minutes, when trading intensity is high, while it takes more than 23 minutes when trading intensity is low. We conjecture that trading intensity could be affected by the precision of information quality. If the information shock that is delivered to the market is interpreted with a greater degree of precision by informed investors, then they trade intensely to quickly incorporate the new information into prices. On the other hand, if the information that is released to the market is subject to ambiguous interpretation by the informed traders, they would take a longer time to assess the impact of the new information and trade more slowly. On average, we expect each stock to have relatively few episodes of intense trading activity followed by normal or low trading activity. Also, the four-minute adjustment period represents a relatively short time within which a trader could exploit market frictions / inefficiencies and make an abnormal profit. ${ }^{13}$ We chose a 5minute interval to measure net-buy volume, quote revision and net depth since we are interested in understanding the dynamic behavior (including feed back effects) that obtains on average. Based on Dufour and Engle's evidence we expect all price adjustments to take place in about 5 lags or less.

\footnotetext{
${ }^{13}$ We are alluding to traders who are not floor-brokers or market-makers who have privileged access to information on transitory market imbalances.
} 
Prior research has documented consistent intraday patterns in volatility, trading volume and depth. Wood, McInish and Ord (1985) were the earliest to document a U-shaped pattern in return volatility during the trading day, volatility being highest at the beginning and at the close of the trading day. Brock and Kleidon (1992) and McInish and Wood (1992) present evidences showing a U-shaped pattern in quoted spreads and trading volumes. Lee, Mucklow and Ready (1993) also find confirmatory evidence on U-shaped patterns in quoted spreads and trading volume. In addition, they also find that effective spreads follow a similar U-pattern, but quoted depths follow a reverse U-pattern. This interrelationship between trading activity and volatility suggests that it is worthwhile to examine all three variables of interest, viz., volatility, trading volume and depth simultaneously in an intraday setting.

According to Foster and Vishwanathan (1993) the day-of-the-week seasonalities in volatility are very weak. The informed traders, however, have incentives to trade earlier in the week before their informational edge is wiped out by public dissemination of their private information. We are not aware of any study that empirically studies intraday patterns in quoted depths.

We incorporate the day-of-the-week and the time-of-the-day effects in studying the interaction of volatility, trading activity and depth. As before, our proxies for the three variables - quote returns, net-buy volumes, and net-depth, are studied using a VAR system of equations with the inclusion of intraday and day-of-the week dummy variables. The expanded version of equations (1)-(3) with dummy variables is as follows:

$$
\begin{aligned}
& r_{t}=\sum_{i=1}^{p} a_{i} r_{t-i}+\sum_{i=0}^{p} b_{i} x_{t-i}+\sum_{i=1}^{p} c_{i} z_{t-i}+\sum_{k=1}^{5} \phi_{k} D_{k t}+\sum_{j=1}^{3} \gamma_{j} I_{j t}+\varepsilon_{t} \\
& x_{t}=\sum_{i=1}^{p} d_{i} x_{t-i}+\sum_{i=1}^{p} e_{i} r_{t-i}+\sum_{i=1}^{p} f_{i} z_{t-i}+\sum_{k=1}^{5} \varphi_{k} D_{k t}+\sum_{j=1}^{3} \lambda_{j} I_{j t}+\eta_{t}
\end{aligned}
$$




$$
z_{t}=\sum_{i=1}^{p} g_{i} z_{t-i}+\sum_{i=1}^{p} h_{i} r_{t-i}+\sum_{i=1}^{p} k_{i} x_{t-i}+\sum_{k=1}^{5} \tau_{k} D_{k t}+\sum_{j=1}^{3} \psi_{j} I_{j t}+\zeta_{t}
$$

where $D_{k t}$ 's are the day-of-the-week dummy variables and $I_{j t}$ 's are the dummy variables to capture time-of-the-day effects. $I_{1 t}$ is equal to 1 during 9:30 a.m. to 10:30 a.m., $I_{2 t}$ is equal to 1 during 12:30 p.m. to $1: 30$ p.m., and $I_{3 t}$ is equal to 1 during 3:00 p.m. to 4:00 p.m.

We examine NYSE as well as NASDAQ stocks to determine whether the institutional features of markets have material effects on the relationship between trades, quotes and depths. The primary institutional differences between the markets include (1) a single specialist on the NYSE versus multiple market makers on the NASDAQ, (2) a call market open on the NYSE versus a quote-driven system that searches for equilibrium prices in the NASDAQ, and (3) the consolidation of order flow through the specialist on NYSE versus the fragmentation of order flow across dealers in NASDAQ [Chan, Christie, and Schultz (1995)].

There exist certain structural differences between the two markets that lead us to expect the dynamic interactions between trading, price volatility and depth to vary across the two markets. First, we expect NYSE to respond more rapidly compared to NASDAQ in identifying and incorporating effects of informed trading. This is because NYSE is a centralized market and specialists are assumed to be in a better position to detect the presence of informed trading. NASDAQ, on the on the hand, operates as a decentralized market in which it is not easy to identify the incidence of informed trading. Second, we expect NASDAQ to be better able to handle shocks in trading volume due to a large number of dealers making the market for the most actively traded stocks. It is commonplace to have about 60 dealers actively making the market for the most active stocks. Third, we expect prices to be less responsive on 
NASDAQ compared to NYSE. On the NASDAQ, there exist certain features, such as internalization and preferencing, which diminish the incentives of dealers to post narrow quotes. A final reason that motivates a comparative study across NYSE and NASDAQ is the recent market reform on NASDAQ. These reforms were phased in on January 20, 1997 with the intention of providing traders with greater opportunities to reduce their trading costs. The most noteworthy of these changes pertains to the requirements that limit orders be executed or exposed to the market, and that favorable prices quoted by NASDAQ market makers on proprietary trading systems be made available to all public market orders. Barclay et. al. (1999) show empirically that these reforms have resulted in a significant $30 \%$ decline in quoted and effective spreads.

Prior to the reform, researchers such as Huang and Stoll (1996) document that quoted spread and other execution costs are twice as large on their sample of NASDAQ stocks as compared to a matched sample of NYSE stocks. Recent work done by Chung, Van Ness and Van Ness (2002) on comparing the liquidity and quotesetting behavior on NYSE and NASDAQ show that despite improvements in NASDAQ, market makers still quote wider spreads than NYSE specialists. Furthermore, their empirical results show that the average quoted depth of NASDAQ stocks is significantly smaller as compared to the quoted depth of a matched sample of NYSE stocks.

\section{Empirical Results}

\section{A. Data}

Our primary dataset consists of trades and quotes from January 3, 2000 to March 31, 2000 on thirty stocks. This sample consists of fifteen stocks selected from the thirty stocks comprising the Dow Jones Industrial Average and fifteen stocks from 
the stocks comprising the NASDAQ 100 Index. Trades and quotes data are obtained from the NYSE Trade and Quote (TAQ) database. ${ }^{14}$ These stocks are the most actively traded stocks in the respective group during the sample period and are most likely to experience frequent flow of information into the market.

We divide each trading day into seventy-eight successive 5-minute intervals when the market is open from 9:30 a.m. through 4:00 p.m. EST. We generate 5minute quote-return series for each stock by calculating the log of the ratio of quote midpoints in successive intervals. We also calculate the net-buy volume and net-depth for every 5-minute interval for each stock. Net-buy volume is the difference between buyer-initiated volume and seller-initiated volume, while net-depth is the difference between ask quote size and bid quote size during the 5-minute interval. We standardize quote return, net-buy volume, and net-depth following Hasbrouck (1988) and Easley, O'Hara, and Srinivas (1998) to control for the cross-sectional variations across stocks. Each day we first calculate the mean and standard deviation of each variable for each stock. We standardize the values of each variable by subtracting the mean and dividing by the standard deviation. Such standardization allows us to pool the entire sample of stocks for statistical analysis so as to increase the power of the tests. $^{15}$

\section{B. Descriptive Statistics}

We provide descriptive statistics regarding quote return, net buy volume and net depth in Table 1. It is of interest to see if quote-return, net depth and net buy

\footnotetext{
${ }^{14}$ The TAQ database reports only the largest depth at the inside market for NASDAQ issues and not the total depth. We recognize this lacuna in the dataset. We follow the example of a recently published paper by Chung and Van Ness (2001) that use depth from the TAQ dataset for their sample of NASDAQ firms.

${ }^{15}$ Before pooling the data, we first generate lagged values of a standardized variable for each day for each stock. We then stack up columns of current and lagged values of variables for a stock for all the trading days in the sample period (i.e., 63 days from January 3 to March 31, 2000). Finally, we stack up all the fifteen stocks in the group to form a pooled sample. We use these pooled observations to calculate autocorrelations and to estimate the VAR model.
} 
volume are in the same direction or not. In the absence of information asymmetry and sub-optimal inventory position of liquidity suppliers, we expect depth to be supplied in response to perceived order in the same direction. That is, if outside investors want to purchase more shares, market makers would supply more depth at the ask. However, when faced with inventory risk or perceived information asymmetry they have incentives to supply less depth in the demanded direction. In panel A, we show the results for the NYSE stocks included in Dow Jones Industrial index. We find that the opening hour, midday and closing hour standardized quote returns average 0.0176 , 0.0166 , and 0.0056 , respectively. We do not observe the familiar U-shaped pattern in intraday return volatility documented in earlier research. A possible reason is that our measure uses quote midpoints rather than transaction prices used in prior studies. Opening hour net buy volume averages -0.0119 indicating selling pressure at the open. Midday shows average values of 0.0033 indicating an abatement of selling pressure. The closing hour average net buy volume is 0.0077 indicating that significant buying takes place at the close. Contrary to prior research we find that intraday standardized net depth values show a J-shaped pattern with opening value of 0.0207 , midday value of -0.0146 and closing hour value of 0.0609 . The pattern indicates that liquidity suppliers have a proclivity to supply more shares for public purchase at the open and during the closing hour. The pattern at the open is probably an appropriate response by liquidity providers to counteract the selling pressure at the open by public traders. The higher net depth at close is perhaps motivated to reduce inventory and therefore overnight exposure. It is interesting to note that specialists provide more depth in the direction opposite to that of net trade flow. This could be their means of managing their inventory position and counteracting a potential order imbalance situation. 
The average standardized quote return increases from 0.0033 on Mondays to 0.0038 on Tuesdays. Interestingly Wednesdays and Thursdays have the highest average values at 0.0088 and 0.0075 , respectively. Fridays have the lowest value of any day of the week at -0.0026 . Standardized net buy volume is lowest on Mondays at -0.0119 . It is indicative of net selling on Mondays consistent with earlier work. It increases somewhat to -0.0018 on Tuesdays. Wednesdays and Thursdays have average standardized net buy volumes of 0.0068 and 0.0008 , respectively. Friday values are on average negative at -0.0041 . Standardized average net depth is lowest on Mondays at 0.0001 . Tuesdays have higher net depth at 0.0007 . Wednesday experiences the highest depth at 0.0068 . Net depth averages are 0.0014 and 0.0052 on Thursday and Friday, respectively. The higher net buy volume on Wednesdays and Thursdays as well as the higher depth on these days is consistent with the resolution of information asymmetry that specialists and other liquidity providers face on Monday after the weekend closure.

In panel $\mathrm{B}$ of Table 1, we report descriptive statistics pertaining to our NASDAQ sample. The intraday pattern in quote returns of our NASDAQ sample is different from that of our NYSE sample. The opening hour average standardized quote return is negative (-0.0400); midday value averages 0.0218 , and closing hour returns are 0.0034 on average. On NASDAQ also, we do not observe the familiar Ushaped pattern in intraday return volatility documented in earlier research. Opening hour net buy volume averages 0.0432 indicating buying pressure at the open. Midday shows average values of -0.0605 indicating selling pressure. Closing hour average net buy volume is 0.0398 indicating that significant net buying takes place at the close. We find that intraday standardized net depth averages $-0.068,-0.0025$ and -0.0309 during the opening hour, midday and closing hour, respectively. In contrast to NYSE, 
where liquidity suppliers have a proclivity to offer more shares for sale to the public at the open and during the closing hour, NASDAQ liquidity suppliers are willing to purchase more shares from the public at the open and during the close. It appears that NASDAQ dealers supply less liquidity at the open and the close compared to NYSE specialists reflecting their relative informational handicap and lack of monopoly power.

The average standardized quote return decreases from 0.0033 on Mondays to 0.0012 on Tuesdays. The quote return reduces further to -0.0041 on Wednesdays. Thursdays have the highest average value of 0.0064 . Fridays have the lowest value of any day of the week at -0.0048 . Standardized net buy volume is negative on Mondays and averages -0.0201 . It is less negative on Tuesdays with an average value of -0.0122 . On Wednesdays and Thursdays the average standardized net buy volumes are -0.0040 and -0.0074 , respectively. Friday values average -0.0209 . It appears that Mondays and Fridays are characterized by net selling on the aggregate with abatement in selling intensity occurring during the middle of the week. Standardized average net depth is positive on Mondays at 0.0065 . Tuesdays have average net depth close to zero. Wednesdays experience negative net depth averaging -0.0116. Net depth averages -0.0028 and -0.0146 on Thursdays and Fridays, respectively.

\section{$=====$ Insert Table 1 about here $======$}

We next calculate autocorrelation for each series. Table 2 presents autocorrelation up to five lags for quote return, net-buy volume, and net-depth for NYSE and NASDAQ stocks. The two net-buy volume series exhibit significant positive autocorrelation at first and subsequent lags, although autocorrelation decays more rapidly as the lag increases. These results are consistent with those of Hasbrouck and Ho (1987) who document positive autocorrelation in the arrival of buy and sell 
orders. The presence of positive autocorrelation in net-buy volume is more consistent with lagged adjustment to new information than the trade reversal consistent with inventory control behavior of market makers. The two quote-return series display significant negative autocorrelation at first and subsequent lags, although autocorrelation decays more rapidly as the lag increases. These results are consistent with the inventory control models. The dealers tend to revise quotes to induce an imbalance in incoming orders that would restore inventory to some desired optimum level. The two net-depth series exhibit significant positive autocorrelation at first and subsequent lags. The positive autocorrelation is indicative of a gradual response by liquidity suppliers to information and liquidity events. The autocorrelation decays more rapidly as the lag increases in NASDAQ as compared to NYSE.

$$
=====\text { Insert Table } 2 \text { about here }=====
$$

C. VAR Estimation Results

We estimate the bivariate VAR model in equations (1)-(2) based on 5-minute intervals. We leave out net-depth in the initial estimation to provide comparability with Hasbrouck's (1991) results. Following Hasbrouck (1991), we estimate each equation separately by the OLS method. We choose the contemporaneous [only for net buy volume in equation (1)] and five lags for each explanatory variable. The results are reported in Table 3. As per our prediction in Figure 1, we find that trades have a direct positive impact on quotes. In NYSE, the contemporaneous and (first) lagged volumes affect quote returns. Some of the lagged volume coefficients have a negative effect on quote returns, indicating a reversal tendency. We interpret this tendency of quote reversals as a correction of an initial overreaction. On the NASDAQ, trades have a large positive contemporaneous impact on quote returns. As in NYSE, the third, fourth, and fifth lags have a negative effect on quote returns. Once 
again, this is consistent with a reversal of the initial positive effect of trades on returns. Our results are similar to those reported by Hasbrouck (1991) although our sample, time aggregation and period of study are different. Further, our study includes the period after the tick size reduction in NYSE and NASDAQ became effective. $^{16}$

The lagged quote returns are significantly negatively related to contemporaneous returns. This is consistent with negative autocorrelation detected in quote-return. These results together imply that the full impact of a trade on the quote revision is not felt instantaneously but with a protracted lag. Our evidence is consistent with the explanation that specialists on the NYSE and dealers on the NASDAQ have an initial tendency to react excessively in setting the quotes when responding to trades. They have a propensity to correct this overreaction subsequently. Overall, these empirical results along with the presence of negative autocorrelation in quote-return admit the simultaneous existence of inventory control and asymmetric information effects in quote revision. These results are consistent with both of these effects. Our results are also consistent with those of Hasbrouck (1991) who finds that the quote midpoint is raised (lowered) subsequent to the arrival of a buy (sell) order. Our results are based on a 5-minute aggregation period while Hasbrouck uses transaction time in his estimation. Further, his results are based on a typical stock - Ames Department Stores, while our results are based on a sample of highly liquid, large market capitalization stocks listed on NYSE and NASDAQ.

$=====$ Insert Table 3 about here $======$

As per our discussion in the previous section, the net impact of lagged quote returns on net buy volume is ambiguous, as the informational effect is expected to be

\footnotetext{
${ }^{16}$ On June 24, 1997, the New York Stock Exchange reduced the minimum price variation for quotes and trades from an eighth to a sixteenth. A similar reduction occurred on NASDAQ on June 2, 1997.
} 
positive while the non-informational (inventory control) effect is predicted to be negative. The $d_{t}$ coefficients are positive and statistically highly significant in both NYSE and NASDAQ providing a clear resolution of the ambiguity. The informational effects dominate the inventory control effects. Our results are also in accordance with prior research by Huang and Stoll (1997) and other work, which show inventory holding costs are relatively unimportant in explaining the quote-setting behavior of market makers.

We find that the coefficients measuring the impact of lagged quote return on net-buy volume are positive and statistically significant for both NYSE and NASDAQ stocks. Although the lagged quote-return appears to have affected the net-buy volume, the sign of the coefficient contradicts what we expect from inventory control effects. Another important feature in the empirical estimation is the strong positive impact of lagged net-buy volume in equation (2). This is consistent with positive autocorrelation found in net-buy volume. These results together imply that the counteracting forces of price pressure effects and order fragmentation dominate inventory control effects in net-buy volume. Our results contradict those of Hasbrouck (1991) who finds negative impact of quote-returns on trades. One of the explanations offered by Hasbrouck (1991) to explain the negative relation between trades and lagged quote returns observed in his study is the possibility of quote reporting errors. We use a longer aggregation period for quote-returns and trades and do not find evidence of a negative relation. Our evidence of a positive relationship between trades and lagged quote returns indicates that informational impact of quote volatility dominates the noninformational (inventory control) effects. The absence of significant inventory control behavior of market makers in an intra-day setting is consistent with the 
findings of Madhavan and Smidt (1993) who find the half-life of specialist inventory to average 7.33 days.

Table 4 provides results of the trivariate VAR estimation. In panel A, we show results for our sample of stocks included in the Dow Jones Industrial index. The quote return regression shows some interesting patterns. The predominantly negative coefficients observed for $a_{1}$ through $a_{5}$ indicate that price shocks (volatility shocks) have a tendency to quickly mean-revert. It also implies that prices have a tendency to overshoot and then quickly revert back. The declining trend in coefficients with greater lags shows that the corrections to the overshoots decay with time. The significant positive values for $b_{0}$ and $b_{1}$ indicate the direct impact of trading activity on price volatility. Large trades tend to have a large impact on prices within a short period of time (within 10 minutes). This effect is somewhat transitory and is reversed in the subsequent intervals of time. The negative $b_{2}-b_{5}$ coefficients are indicative of downward revision of quotes by specialists after increases in prior periods in response to perceived information contained in the trades. It appears as though specialists are initially inferring more information content in trades and subsequently revising the level of information content downwards. This appears as a correction to an initial overreaction. The negative and significant $c_{1}$ coefficient indicates that the lagged depth of a stock dampens the price movements. Stocks, which have greater buy depths, exhibit subsequent lower volatility on the buy side other things being equal. The negative relation indicates that quote returns tend to be negative in the periods following increases in net depth. The observed empirical results are in accordance with our predictions outlined in Figure 1.

\footnotetext{
$=====$ Insert Table 4 about here $======$
} 
The net-buy volume regression shows the dynamic impacts of lagged volume, quote return and depth. The positive and statistically significant values for $d_{1}$ through $\mathrm{d}_{5}$, highlight the persistence in volume shocks. The effect of a large volume shock persists in subsequent 5-minute intervals and decay somewhat slowly with time. The positive and statistically significant $\mathrm{e}_{1}-\mathrm{e}_{5}$ coefficients indicate that lagged quote returns have a positive impact on net buy volume and this effect slowly decays with time. The fact that there are no negative 'e' coefficients indicates that we are unable to observe the impact of quote revision behavior of specialists. When faced with a buying pressure, specialists have incentives to revise their bid and ask quotes upwards. This would provide a positive quote return in the given period. The higher bid quote is designed to induce some traders to sell to the specialist resulting in a realized negative figure for the net-buy volume in a subsequent period. Our inability to observe this effect is perhaps driven by specialists having a cycle longer than 30 minutes for equilibrating their inventory. The positive and significant $f_{1}$ coefficient indicates that lagged depth contributes positively to net-buy volume. There does not seem to be a persistence effect in depths, since lag lengths greater than one do not have a significant impact on volume.

The net-depth estimation resolves some of the ambiguities documented in Figure 1. First, the estimates of $h_{t}$ coefficients facilitate a resolution of the ambiguity that we presented in Figure 1 that relates to the impact of quote volatility on depth. Non-informational quote volatility is expected to impart a positive effect on depth, while the informational impact is predicted to be negative. The net effect is positive for our sample of NYSE stocks, demonstrating that the NYSE is better equipped to absorb informational effects. Liquidity providers such as specialists respond to large movements in quotes by offering to trade large quantities. The net-depth estimation 
results for our sample of NASDAQ stocks indicates that $h_{1}$ is significantly negative. This indicates that lagged volatility (of length 1) depletes current depth. This finding is in stark contrast with our findings of the NYSE sample. There are two possible explanations for this observation. Market makers when faced with a volatility shock respond by quoting lower depth. This is due to the adverse information risk that they may perceive. A second possible reason is the rather thin limit order book that NASDAQ stocks have in comparison to NYSE stocks. When prices move rapidly, trades consume most of existing market maker quotes and limit orders. The resulting thin book exhibits lower depth. The positive $h_{2}$ through $h_{5}$ coefficients indicate that depth replenishment does take place for NASDAQ stocks albeit at a slower rate than for NYSE stocks. It signifies that specialists on the NYSE who have privileged access to the order book are better able to gauge the presence of informed investors as compared to dealers in the NASDAQ. ${ }^{17}$ The positive and significant $g_{t}$ coefficients indicate persistence in depths. Lagged depths tend to positively impact current depth. Similar results are obtained for both the NYSE and the NASDAQ samples.

A second uncertainty is resolved when we observe the $k_{t}$ coefficients. For the NYSE sample we observe that the $\mathrm{k}_{1}$ coefficient is negative and significant. This finding indicates that a large volume shock in the prior period depletes the current depth on NYSE. However, depth is restored to previous levels rather rapidly as evidenced by insignificant coefficients at longer lags. Interestingly, we find the exact opposite results in our NASDAQ sample. $k_{1}$ is positive and statistically significant. This finding indicates that the competitive market structure in NASDAQ facilitates a rather quick replenishment of depth in response to trading volume shocks. We obtain similar results at longer lag lengths for NASDAQ and NYSE stocks.

\footnotetext{
${ }^{17}$ On the NASDAQ, it is likely that a large order executes simultaneously with several dealers' quotes and results in a significant quote movement. It is reasonable to expect dealers to take a longer time to assess the informational impact of a large quote revision.
} 
We then estimate the VAR model with the day-of-the-week and the time-ofthe-day dummy variables. The results (not reported) do not indicate any material effects on the relationship among quote-return, net-buy volume and net-depth. There are no major changes in the sign, magnitude, and statistical significance of coefficients of explanatory variables. However, we are successful in detecting some day-of-the-week and time-of-the-day effects in the interaction of trades and quote revision. These results are presented in Table 5. None of the day-of-the-week dummy variables has statistically significant coefficient for quote return, net-buy volume or net-depth equations for NYSE Stocks. For NASDAQ stocks, we find statistically significant coefficients for dummy variables for all but one (Thursday) day-of-theweek dummy variables in the net-buy volume equation. None of the day-of-the-week dummy variables has statistically significant coefficient for quote-return equation of NASDAQ stocks. For net-depth equation of NASDAQ stocks, the dummy variable is statistically significant only for Monday.

\section{$======$ Insert Table 5 about here $======$}

It is of interest to see if the opening hour volatility, volume and depth are different from those during the rest of the day. Prior research has documented a Ushaped pattern in volatility with highest volatility during the start of the trading day and at the close. A similar effect has also been observed in trading volume with highest volume at the start of the day, a significant decline during the trading day and a jump in volume at the close. A reverse U-shaped pattern in depth has been observed by earlier research. Since we use a VAR system for estimation, we are able to account for simultaneous variation across our three variables of interest: volume, volatility and depth. Foster and Vishwanathan (1993) provide a model in which informed traders trade before their private knowledge becomes public. They attribute the heavy trading 
at the open to this phenomenon. Also, trades are more informative at the open due to trading activities of informed traders and this leads to higher volatility at the start of the trading day. Our results for NYSE stocks in Panel A show a negative and significant quote return during the opening hour. The net-buy volume shows a small insignificant increase at the open. Net-depth also exhibits a minor rise at the open. The systematic pattern in the quote return indicates that the market makers are particularly over-sensitive to bad news (sell orders) at the start of the trading day. This potential mis-pricing seems to be corrected at the mid-day when quote-returns are positive and statistically significant. This correction seems to be occurring without perceptible surges either in volume or depth. There is no systematic pattern in quotereturns during the closing hour. Net depth is highest at the close when prices are most efficient. The higher ask depth at the close is also indicative of specialist's efforts to reduce their overnight exposure.

For NASDAQ stocks, we find a pattern in quote returns that is similar to NYSE stocks. The opening hour returns are negative and statistically significant, at mid-day the returns are positive and finally at the close there is no perceptible change in returns. Our evidence is indicative of an overreaction to bad news at the start of the trading day with a substantial correction during the mid-day. Closing prices are efficient in the sense that there seems to be no systematic pattern. There is a significant surge in net-buy volume during the opening hour, a decline during the mid-day and an increase during the closing hour. Perhaps, strategic traders adopt contrarian positions to exploit the temporary mis-pricing during the opening hour. They may be liquidating their positions at mid-day when the mis-pricing is corrected. Interestingly, net-buy volume is high at the closing hour when pricing is most efficient. Discretionary liquidity traders could be buying stocks and this could be a 
contributing factor to the surge in volume. Short sellers could also be unwinding their positions at the end of the trading day to avoid exposure to overnight information. There is a significant decline in depth at the open, a return to normal levels at mid-day and a further decline during the closing hour. The decline at the open could be a consequence of higher net-buy volume during the opening hour depleting the supplied depth. Furthermore, it could reflect the reluctance of liquidity suppliers to provide additional depth as it would increase their potential exposure during periods of perceived high adverse information. Net depth is normal around mid-day even though net-buy volume is negative. It indicates that liquidity suppliers respond rather quickly during this period. Finally, the reduction in net depth at the close could be due to the combination of higher buy volume at the close and a desire to reduce overnight exposure by the market makers.

Our finding clearly elucidates the important difference between NYSE and NASDAQ in providing depth during periods of high perceived adverse information such as the opening and closing period. Net buy volume and net depth are in the same direction in NYSE indicating that specialists are able to discern the presence of informed trades more clearly on average during the open and closing periods. On the other hand, NASDAQ market makers respond during periods of information asymmetry, such as the opening and closing hour, by not replenishing depth that is consumed by ensuing order flow. This finding is consistent with our earlier observation that NYSE specialists are better equipped to deal with information asymmetry as compared to NASDAQ.

D. Impulse Response Analysis

As we outlined in Figure 1, there are 3 ambiguities which theory fails to resolve. Our VAR tests are designed to resolve them on average. Also our VAR tests 
masks any time variation in the patterns of response. We employ impulse response analysis to resolve the ambiguities and portray time variations during specific episodes of perceived high and low information asymmetry. We select two stocks from NYSE (Dow sample) and two from NASDAQ. We search for two episodes in each market: an event, which involves an event that exacerbates the information asymmetry and another event that does not. Accordingly, we select the following four stocks: Dell and Microsoft on NASDAQ and Disney and Wal-Mart on NYSE.

Our first candidate for conducting impulse response analysis pertains to an event affecting Walt Disney Company. Walt Disney is listed on the NYSE and is included in our sample of NYSE stocks. On January 10, 2000, AOL and Time Warner announced their intention to merge. This announcement led to widespread speculation that other media giants and internet firms were also engaged in merger talks with the objective of countering the dominance of the merged AOL-Time Warner Company. Companies such as Microsoft, Yahoo, News Corp and Walt Disney prominently featured in these rumors. In particular, there were strong rumors that Walt Disney was engaged in merger talks with Yahoo. Finally, on January 12, 2000, Yahoo quashed these rumors setting at rest, the speculation that Yahoo and Walt Disney were negotiating a merger deal.

We study this event to examine the impact of information asymmetry on the trade-quote-depth dynamics. We expect the greatest information asymmetry on January 10 and a gradual resolution by January 12 . The results of the impulse response analysis are reported in Figure 2. In Panel A, we show the results obtained on January 10. In particular, we observe the response of depth to innovations in quotereturns and volume. Depth responds positively to the quote return shock indicating that the non-informational effect dominates. This result accords well with our findings 
using VAR estimation as reported in Table 4. In striking contrast to the depth reaction to the return shock, the response of depth to a volume shock indicates that the informational effect is stronger as compared to the non-informational effect. This finding implies that liquidity suppliers are cautious in responding to a volume shock since they perceive an escalation in the extent of informational trading. Once again, this finding confirms our previous finding from the VAR estimation. Finally on examination of the volume response to the return shock, we observe a positive impact indicating that informational effects dominate the inventory control (noninformational) effect.

In Panel B of Figure 2, we show impulse response results obtained on January 11. A partial resolution of information asymmetry is evident when we observe the depth response to a volume shock. Finally in Panel C, we report results observed on January 12. It is quite apparent that depth responds positively to a volume shock indicating that the non-informational effects are prevailing. We interpret this finding to mean that liquidity providers are sensitive to perceived information asymmetry and they update their response according to changing perceptions.

$$
=====\text { Insert Figure } 2 \text { about here }======
$$

The next event we choose for our impulse response analysis concerns an episode relating to Dell Computers. On March 13, 2000, influential analyst Dan Niles upgraded Dell. This event can be characterized as a volatility shock akin to an insider revealing his private information to the public. The upgrade resulted in a massive surge in the stock price of Dell. By the end of the trading day, Dell's stock price soared by $6.8 \%$. By mid-morning on the next trading day prices rose another $4.5 \%$. In Figure 3, we show the impulse response analysis for Dell Computers on March 10, 13, and 14 in panels A, B, and C, respectively. We use March 10, as the base case to 
study the behavior of trades, quotes and depth on March 13 and March 14. The depth response to a return shock on March 10 reveals that liquidity providers exercise extreme caution in the aftermath of a return shock fearing the consequences of adverse selection. Observing the depth response to a volume shock, we are able to conclude that liquidity providers are better able to cope with a volume shock than a return shock. On examining the volume response to a return shock, we are able to discern a mild demonstration of inventory control behavior. The results for March 13, shown in Panel B, reveal deterioration in depth in response to a volume shock. This finding indicates that the informational effects seem to be dominating the noninformational effect. Liquidity providers seem to be exercising due vigilance when they confront a volume shock and respond by supplying a lower quantity of depth. As before, depth responds negatively to a return shock. The results reported in Panel C for March 14 indicate a remarkable improvement in the response of depth to return and volume shocks. This indicates that market makers now consider information effects of trades and quote movements to be less important.

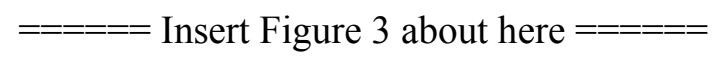

The third event we study relates to the news item regarding Microsoft's offer to settle federal antitrust charges. Microsoft presented its proposal to the government on March 23, 2000. Given the uncertainty associated with the acceptance of Microsoft's proposal by the federal government, we expect a heightened degree of information asymmetry on the announcement day, viz., March 23. On March 27, government lawyers reported that they considered the offer to be inadequate and announced their intention to reject it. Observing the impulse response curves for March 23 as portrayed in panel A of Figure 4, we perceive clear evidence of the extremely cautious behavior of liquidity providers. The depth response to return and 
volume shocks show an oscillatory pattern that carries through to the volume and quote returns. The strong negative response of depth to volume and return shocks indicates the dominating influence of informational effects. The informational effects continue to dominate on March 24, the next trading day, as reported in panel B, but there are no oscillations. Finally on March 27, when the information asymmetry is resolved depth responds positively to a volume shock indicating the overriding influence of non-informational effects. However, depth response to return shocks continues to be negative signifying the continued cautious behavior of liquidity providers.

\section{$=====$ Insert Figure 4 about here $=====$}

The last event we study can be characterized as predominantly a volume shock. On March 30, 2000, the influential equity strategist Ms. Abbey Joseph Cohen pronounced that technology stocks were fairly priced and that investors should sell part of their holdings. The NASDAQ index lost about $2.5 \%$ on that day due to the sell-off in major technology stocks. Interestingly, investors parked their money in pharmaceuticals and retail stocks such as Wal-Mart. There were no significant announcements or information releases from Wal-Mart on that day. So, we select Wal-Mart and use this event as an example of volume shock. The impulse response analysis results are shown for March 29, and 30 in panels A, and B, respectively of Figure 5. March 30 is the event day. Response curves are also shown on the day before (March 29) for comparison. We find the depth response to a volume shock particularly interesting. Although, the day is not characterized as an information event, depth is less profuse compared to the non-event days. In contrast to the rapid depletion of depth witnessed during periods of high information asymmetry (as in the case of Walt Disney and Microsoft), dealers are more forthcoming in supplying 
liquidity. Also, in comparison with the impulse response curves of Dell Computers (a NASDAQ firm), Wal-Mart, which is listed on the NYSE seems to be better able to cope with volume shocks.

$=====$ Insert Figure 5 about here $=====$

In conclusion, the impulse response curves have served to confirm our findings from the VAR estimation that NYSE specialists respond better with a higher quantity of depth when confronted with volatility shocks as compared to NASDAQ dealers. On the other hand, NYSE specialists perform worse compared to their peers on the NASDAQ when dealing with volume shocks. An interesting finding that clearly emerges from our impulse response analysis is that NYSE specialists are able to dynamically adapt their behavior in quoting depth in accordance with their perception of information asymmetry. When the hazard of adverse selection appears minimal, NYSE specialists respond enthusiastically in a more positive manner while responding to volume shocks. We find the empirical results in accordance with our expectation that market structure is relevant and that NYSE specialists possess an edge in processing information even during periods of high degree of perceived information asymmetry.

\section{Concluding Remarks}

We have examined the dynamic interaction between return volatility, trading volume and depth in an intraday setting for a sample of actively traded NYSE and NASDAQ stocks. Our principal contribution has been to add the third dimension of depth to the earlier framework that studied the interactions between trading activity and return volatility. We have shown empirically that depth is a useful intervening variable and tends to mitigate the impact of trading activity on price volatility. A second contribution is our effort to develop predictions regarding the direction of 
impact of each predictor variable on the dependent variables. For instance, the provision of depth is affected by the perception of prevailing information asymmetry between informed and uninformed traders. An increase in trading activity causes depth to go up when trades are assumed to be non-informational. On the other hand, trades suspected to be information-driven aggravate the perceived information asymmetry and cause a decrease in depth. Likewise, information-driven price volatility changes result in depth decreases while non-informational changes produce an increase in depth. We have outlined using market microstructure theory, strong reason to expect bi-directional causality between the three variables of interest: trading activity, price volatility, and quoted depth. Our predictions are unambiguous in three out of six cases. We conduct empirical tests using VAR methodology to resolve the ambiguities in the other three cases. The first ambiguity concerns the net impact of quote revisions on trades. The overall effect is positive in both NYSE and NASDAQ stocks signifying that the informational effect dominates the noninformational effects. The net impact of trades on depth represents the second ambiguity. The net effect is negative on the NYSE, but positive on NASDAQ. Evidently, market structure plays a role in the trade-depth dynamics in stock markets. Lastly, the net impact of quote revisions on depth is positive on NYSE while it is negative on NASDAQ. Seemingly, NYSE handles volatility shocks better and supplies greater depth.

As a third contribution, we examine whether market structure has an effect on the observed trade-quote-depth dynamics. We demonstrate empirically that NYSE supplies greater depth under conditions of high, perceived information asymmetry as compared to NASDAQ. NASDAQ makes up for this deficiency by its capability of managing large volume shocks without a major decline in depth. As a final 
contribution, we deal with the issue of whether liquidity providers vigorously adjust their strategies in reaction to changing conditions of information asymmetry. We study several informational events to show that liquidity providers exercise caution by offering less depth during periods of high information asymmetry while responding with a more generous supply of depth at other times. We surmise that this difference could be driven by the better price discovery and lower information asymmetry on NYSE under the direction of the monopoly specialist, while the multiple dealer structure of the NASDAQ market exposes liquidity suppliers to greater information risks. Additionally the preferencing arrangements in NASDAQ may preclude some liquidity providers from advertising their depth publicly to reduce their exposure to information risk. Our final observation relates to the response of depth in the two markets following volume shocks. The NASDAQ market responds better providing a faster replenishment of consumed liquidity as compared to NYSE. Perhaps the multidealer competitive market structure in NASDAQ facilitates a quicker response compared to the monopoly structure in market making of NYSE. 


\section{REFERENCES}

Admati, A., Pfleiderer, P., 1988, "A Theory of Intraday Patterns: Volume and Price Variability," Review of Financial Studies, 1, 3-40.

Ahn, H. J., Bae, K. H., and Chan, K., 2001, "Limit Orders, Depth, and Volatility: Evidence from the Stock Exchange of Hong Kong", Journal of Finance, 56, 767-788.

Barclay, M. J., Christie, W. G., Harris, J.H., Kandel E., and Schultz, P. H., 1999, "Effects of Market Reform on the Trading Costs and Depths of NASDAQ Stocks," Journal of Finance, 54, 1-34.

Bessembinder, H., and Seguin, P., 1992, "Futures-trading Activity and Stock Price Volatility," Journal of Finance, 47, 2015-2034.

Bessembinder, H., and Seguin, P., 1993, "Price Volatility, Trading Volume, and Market Depth: Evidence from Futures Markets," Journal of Financial and Quantitative Analysis, 28, 21-39.

Brock, W., and Kleidon, A., 1992, "Periodic Market Closure and Trading Volume: A Model of Intraday Bids and Asks," Journal of Economic Dynamics and Control, 16, 451-489.

Chan, K., Chung, Y., and Fong, W., 2002, "The Informational Role of Stock and Option Volume," Review of Financial Studies, 15, 1049-1075.

Chan, K., and Fong, W., 2000, "Trade Size, Order Imbalance, and the VolatilityVolume Relation," Journal of Financial Economics, 57, 247-273.

Chan, K., Christie, W., and Schultz, P., 1995, "Market Structure and the Intraday Pattern of Bid-Ask Spreads for NASDAQ Securities," Journal of Business, 68, $35-60$.

Chung, K. H., and Chuwonganant, C., 2002, "Tick Size and Quote Revisions on the NYSE," Journal of Financial Markets, 5, 391-410.

Chung, K. H., and Van Ness R.A., 2001, "Order Handling Rules, Tick Size, and the Intra-day Pattern of Bid-ask Spreads for NASDAQ Stocks", Journal of Financial Markets, 4, 143-161.

Chung, K. H., Van Ness, B.F., and Van Ness R.A., 2001, "Can the Treatment of Limit Orders Reconcile the Differences in Trading Costs between NYSE and NASDAQ Issues?" Journal of Financial and Quantitative Analysis, 36, 267286.

Chung, K. H., Van Ness, B.F., and Van Ness R.A., 2002, "Spreads, Depths, and Quote Clustering on the NYSE and NASDAQ: Evidence After the 1997 securities and Exchange Commission Rule Changes," Financial Review, 37, 481-505. 
Copeland, T., and Galai, D., 1983, "Information Effects on the Bid-Ask Spread," Journal of Finance, 38, 1457-1469.

Dufour, A., and Engle, R.F., 2000, "Time and Price Impact of a Trade", Journal of Finance, 55, 2467-2498.

Easley, D., and O'Hara, M., 1987, "Price, Trade Size, and Information in Securities Markets," Journal of Financial Economics, 19, 69-90.

Easley, D., O'Hara, M., and Srinivas, P., 1998, "Option Volume and Stock Prices: Evidences on Where Informed Traders Trade," Journal of Finance, 53, 431465.

Foster, F., and Vishwanathan, S., 1990, "A Theory of Interday Variations in Volumes, Variances and Trading Costs in Securities Markets," The Review of Financial Studies, 3, 593-624.

Foster, F., and Vishwanathan, S., 1993, "Variations in Trading Volume, Return Volatility and Trading Costs: Evidence on Recent Price Formation Models," Journal of Finance, 48, 187-211.

Fung, H., and Patterson, G., 1999, “The Dynamic Relationship of Volatility, Volume, and Market Depth in Currency Futures Markets," Journal of International Financial Markets, Institutions and Money, 9, 33-59.

Glosten, L., and Harris, L., 1988, "Estimating the Components of the Bid/Ask Spread," Journal of Financial Economics, 21, 123-142.

Glosten, L., and Milgrom, P., 1985, "Bid, Ask and Transaction Prices in a Specialist Market with Heterogeneously Informed Traders," Journal of Financial Economics, 14, 71-100.

Goldstein, M. A., and Kavajecz, K. A., 2000, "Eighths, Sixteenths, and Market Depth: Changes in Tick Size and Liquidity Provision on the NYSE," Journal of Financial Economics, 56, 125-149.

Harris, L., 1989, "A Day-end Transaction Price Anomaly," Journal of Financial and Quantitative Analysis, 24, 29-45.

Hasbrouck, J., 1988, "Trades, Quotes, Inventories, and Information," Journal of Financial Economics, 22, 229-252.

Hasbrouck, J., 1991, "Measuring the Information Content of Stock trades," Journal of Finance, 46, 179-207.

Hasbrouck, J., and Ho, T., 1987, "'Order Arrival, Quote Behavior and the Return Generating Process," Journal of Finance, 42, 1175-1199. 
Ho, T., and Stoll, H., 1981, "Optimal Dealer Pricing under Transactions and Return Uncertainty," Journal of Financial Economics, 9, 47-73.

Ho, T., and Stoll, H., 1983, "The Dynamics of Dealer Markets under Competition," Journal of Finance, 38, 1053-1074.

Huang, R., and Stoll, H., 1994, "Market Microstructure and Stock Return Predictions," Review of Financial Studies, 7, 179-213.

Huang, R., and Stoll, H., 1996, "Dealer versus auction markets: A paired comparison of execution costs on NASDAQ and the NYSE," Journal of Financial Economics, 41, 313-357.

Huang, R., and Stoll, H., 1997, "The Components of the Bid-Ask Spread: A General Approach," Review of Financial Studies, 10, 995-1034.

Jain, P., and Joh, G., 1988, "The Dependence Between Hourly Prices and Trading Volume," Journal of Financial and Quantitative Analysis, 23, 269-283.

Jones, M. J., and Lipson, M. L., 2001, "Sixteenths: Direct Evidence on Institutional Execution Costs", Journal of Financial Economics, 59, 253-278.

Jones, M. J., Kaul, G., and Lipson, M. L., 1994, "Transactions, Volume, and Volatility”, Review of Financial Studies, 7, 631-651.

Karpoff, J. M., 1987, "The Relation Between Price Changes and Trading Volume: A Survey", Journal of Financial and Quantitative Analysis, 22, 109-126.

Kavajecz, K. A., 1999, “The Specialist's Quoted Depth and the Limit Order Book", Journal of Finance, 54, 747-771.

Kumar, R., Sarin, A., and Shastri, K., 1998, "The Impact of Options Trading on the Market Quality of the Underlying Security: An Empirical Analysis", Journal of Finance, 53, 717-732.

Kyle, A., 1985, "Continuous Auctions and Insider Trading," Econometrica, 53, 13151335.

Lee, C., and Ready, M., 1991, "Inferring Trade Direction from Intradaily Data," Journal of Finance, 46, 733-746.

Lee, C., Mucklow, B., and Ready, M., 1993, "Spreads, Depths, and the Impact of Earnings Information: An Intraday Analysis," Review of Financial Studies, 6, 345-374.

Madhavan, A., Richardson, M., and Roomans, M., 1997, "Why Do Security Prices Changes A Transaction Analysis of NYSE Stocks," Review of Financial Studies, 10, 1035-1064. 
Madhavan, A., and Smidt, S., 1993, "An Analysis of Changes in Specialist Inventories and Quotations," Journal of Finance, 48, 1595-1628.

McInish, T., and Wood, R., 1992, "An Analysis of Intraday Patterns in Bid/Ask Spreads for NYSE Stocks," Journal of Finance, 47, 753-764.

Stoll, H., 1976, "Dealer Inventory Behavior: An Empirical Investigation of NASDAQ/NMS Stocks," Journal of Financial and Quantitative Analysis, 11, 359-380.

Stoll, H., 1978, "The Supply of Dealer Services in Securities Markets," Journal of Finance, 33, 1133-1151.

Stoll, H., 1989, "Inferring the Components of the Bid-Ask Spread: Theory and Empirical Tests," Journal of Finance, 44, 115-134.

Wood, R., McInish, T., and Ord, J., 1985, "An Investigation of Transaction Data for NYSE Stocks," Journal of Finance, 40, 723-741.

Xu, X. E., and Wu, C., 1999, “The Intraday Relation between Return Volatility, Transactions and Volume", International Review of Economics and Finance, $8,375-397$. 


\section{Figure 1}

\section{Predicted Direction of Impact between Trade, Quote, and Depth}

\begin{tabular}{|l|l|c|c|c|c|c|}
\hline Type of Impact & Q $>\mathrm{T}$ & $\mathrm{T} \triangleright \mathrm{Q}$ & $\mathrm{T} \triangleright \mathrm{D}$ & $\mathrm{D} \triangleright \mathrm{T}$ & $\mathrm{D} \triangleright \mathrm{Q}$ & $\mathrm{Q}$ D \\
\hline Informational & Positive & Positive & Negative & & & Negative \\
\hline Non-informational & Negative & Positive & Positive & Positive & Negative & Positive \\
\hline Net Impact & Uncertain & Positive & Uncertain & Positive & Negative & Uncertain \\
\hline
\end{tabular}

Note: Q denotes Quote revisions our measure of volatility; T denotes Net Buy Volume, our proxy for directional trade; and finally D represents Net Depth, our measure of directional depth. 
Table 1

Descriptive Statistics of Standardized 5-Minute Net-Buy Volume, Quote-Return and NetDepth

\section{Panel A: NYSE Stocks}

\begin{tabular}{lccc}
\hline & Quote Return & Net-Buy Volume & Net-Depth \\
\hline & & & \\
Monday & 0.0033 & -0.0119 & 0.0001 \\
Tuesday & 0.0038 & -0.0018 & 0.0007 \\
Wednesday & 0.0088 & 0.0068 & 0.0068 \\
Thursday & 0.0075 & 0.0008 & 0.0014 \\
Friday & -0.0026 & -0.0041 & 0.0052 \\
& & & \\
Opening Hour & 0.0176 & -0.0119 & 0.0207 \\
Mid-day & 0.0166 & 0.0033 & -0.0146 \\
Closing Hour & 0.0056 & 0.0077 & 0.0609
\end{tabular}

\section{Panel B: NASDAQ Stocks}

$\begin{array}{lrrr}\text { Monday } & 0.0033 & -0.0201 & 0.0065 \\ \text { Tuesday } & 0.0012 & -0.0122 & 0.0000 \\ \text { Wednesday } & -0.0041 & -0.0040 & -0.0116 \\ \text { Thursday } & 0.0064 & -0.0074 & -0.0028 \\ \text { Friday } & -0.0048 & -0.0209 & -0.0146 \\ & & & \\ \text { Opening Hour } & -0.0400 & 0.0432 & -0.0680 \\ \text { Mid-day } & 0.0218 & -0.0605 & -0.0025 \\ \text { Closing Hour } & 0.0034 & 0.0398 & -0.0309\end{array}$


Table 2

Autocorrelation of Standardized 5-Minute Net-Buy Volume, Quote-Return and Net-Depth

\begin{tabular}{llll}
\hline Lag & Net-Buy Volume & Quote-Return & Net-Depth \\
\hline
\end{tabular}

Panel A: NYSE Stocks

$\begin{array}{llll}1 & .124^{*} & -.147^{*} & .327^{*} \\ 2 & .060^{*} & -.016^{*} & .133^{*} \\ 3 & .049^{*} & -.011^{*} & .080^{*} \\ 4 & .036^{*} & -.012^{*} & .049^{*} \\ 5 & .029^{*} & -.012^{*} & .029^{*}\end{array}$

Panel B: NASDAQ Stocks

$\begin{array}{llll}1 & .092^{*} & -.0001 & .116^{*} \\ 2 & .047^{*} & -.009^{*} & .042^{*} \\ 3 & .027^{*} & -.036^{*} & .016^{*} \\ 4 & .017^{*} & -.024^{*} & .008^{*} \\ 5 & .002 & -.023^{*} & -.003\end{array}$

* Significant at the .01 level 
Table 3

\section{Estimates of the VAR Model for Net-Buy Volume and Quote-Return}

The Model is:

$$
r_{t}=\sum_{i=1}^{5} a_{i} r_{t-i}+\sum_{i=0}^{5} b_{i} x_{t-i}+\varepsilon_{t} ; \quad x_{t}=\sum_{i=1}^{5} c_{i} x_{t-i}+\sum_{i=1}^{5} d_{i} r_{t-i}+\eta_{t}
$$

where $r_{t}$ is the quote-return at time $t$ and $x_{t}$ is the net-buy volume at time $t$.

Panel A: NYSE Stocks

\begin{tabular}{|c|c|c|c|c|c|}
\hline & Coeff. & T-ratio & & Coeff. & T-ratio \\
\hline$a_{1}$ & -.172 & -44.86 & $c_{1}$ & . 101 & 25.90 \\
\hline$a_{2}$ & -.053 & -13.66 & $c_{2}$ & .031 & 7.96 \\
\hline$a_{3}$ & -.027 & -7.15 & $c_{3}$ & .029 & 7.38 \\
\hline$a_{4}$ & -.022 & -5.93 & $c_{4}$ & .020 & 5.19 \\
\hline$a_{5}$ & -.017 & -4.66 & $c_{5}$ & .017 & 4.44 \\
\hline$b_{0}$ & .198 & 52.43 & & & \\
\hline$b_{1}$ & .018 & 4.65 & $d_{1}$ & .055 & 14.30 \\
\hline$b_{2}$ & -.011 & -2.77 & $d_{2}$ & .041 & 10.50 \\
\hline$b_{3}$ & -.019 & -5.00 & $d_{3}$ & .028 & 7.29 \\
\hline$b_{4}$ & -.006 & -1.53 & $d_{4}$ & .017 & 4.38 \\
\hline$b_{5}$ & -.009 & -2.43 & $d_{5}$ & .006 & 1.54 \\
\hline
\end{tabular}

\section{Panel B: NASDAQ Stocks}

\begin{tabular}{lccccc}
\hline & Coeff. & T-ratio & & Coeff. & T-ratio \\
\hline$a_{1}$ & -.021 & -5.47 & $c_{1}$ & .049 & 12.68 \\
$a_{2}$ & -.018 & -4.61 & $c_{2}$ & .023 & 6.05 \\
$a_{3}$ & -.038 & -9.80 & $c_{3}$ & .015 & 3.93 \\
$a_{4}$ & -.023 & -6.01 & $c_{4}$ & .011 & 2.81 \\
$a_{5}$ & -.021 & -5.65 & $c_{5}$ & -.000 & -.06 \\
$b_{0}$ & .093 & 23.67 & & & \\
$b_{1}$ & .001 & .21 & $d_{1}$ & .205 & 54.57 \\
$b_{2}$ & -.011 & -2.76 & $d_{2}$ & .085 & 22.28 \\
$b_{3}$ & -.007 & -1.80 & $d_{3}$ & .037 & 9.73 \\
$b_{4}$ & -.011 & -2.78 & $d_{4}$ & .024 & 6.31 \\
$b_{5}$ & -.008 & -2.04 & $d_{5}$ & .019 & 5.25
\end{tabular}


Table 4

Estimates of the VAR Model for Quote-Return, Net-Buy Volume and Net-Depth

The Model is: $r_{t}=\sum_{i=1}^{5} a_{i} r_{t-i}+\sum_{i=0}^{5} b_{i} x_{t-i}+\sum_{i=1}^{5} c_{i} z_{t-i}+\varepsilon_{t}$;

$$
\begin{aligned}
& x_{t}=\sum_{i=1}^{5} d_{i} x_{t-i}+\sum_{i=1}^{5} e_{i} r_{t-i}+\sum_{i=1}^{5} f_{i} z_{t-i}+\eta_{t} \\
& z_{t}=\sum_{i=1}^{5} g_{i} z_{t-i}+\sum_{i=1}^{5} h_{i} r_{t-i}+\sum_{i=1}^{5} k_{i} x_{t-i}+\varphi_{t}
\end{aligned}
$$

where $r_{t}$ is the quote-return, $x_{t}$ is the net-buy volume, and $z_{t}$ is net-depth at time $t$.

\begin{tabular}{|c|c|c|c|c|c|c|c|c|}
\hline & Coeff. & T-ratio & & Coeff. & T-ratio & & Coeff & T-ratio \\
\hline$\overline{a_{1}}$ & -.174 & -45.42 & $\mathrm{~d}_{1}$ & .098 & 24.86 & $g_{1}$ & .312 & 80.17 \\
\hline$a_{2}$ & -.051 & -13.17 & $\mathrm{~d}_{2}$ & .031 & 7.92 & $g_{2}$ & .018 & 4.35 \\
\hline$a_{3}$ & -.025 & -6.47 & $\mathrm{~d}_{3}$ & .029 & 7.29 & $g_{3}$ & .028 & 6.78 \\
\hline$a_{4}$ & -.020 & -5.30 & $\mathrm{~d}_{4}$ & .020 & 5.10 & $g_{4}$ & .012 & 2.92 \\
\hline$a_{5}$ & -.016 & -4.12 & $\mathrm{~d}_{5}$ & .017 & 4.26 & $g_{5}$ & .006 & 1.39 \\
\hline$b_{0}$ & .199 & 52.84 & & & & & & \\
\hline$b_{1}$ & .022 & 5.66 & $\mathrm{e}_{1}$ & .057 & 14.68 & $h_{1}$ & .104 & 26.55 \\
\hline$b_{2}$ & -.010 & -2.45 & $\mathrm{e}_{2}$ & .038 & 9.73 & $h_{2}$ & .072 & 18.09 \\
\hline$b_{3}$ & -.019 & -4.77 & $\mathrm{e}_{3}$ & .026 & 6.61 & $h_{3}$ & .059 & 14.94 \\
\hline$b_{4}$ & -.005 & -1.20 & $\mathrm{e}_{4}$ & .015 & 3.74 & $h_{4}$ & .036 & 9.11 \\
\hline$b_{5}$ & -.008 & -2.08 & $\mathrm{e}_{5}$ & .005 & 1.20 & $h_{5}$ & .029 & 7.39 \\
\hline$c_{1}$ & -.035 & -9.14 & $f_{1}$ & .037 & 9.54 & $k 1$ & -.015 & -3.66 \\
\hline $\mathrm{c}_{2}$ & -.006 & -1.44 & $f_{2}$ & -.005 & -1.31 & $k 2$ & .000 & .08 \\
\hline$c_{3}$ & -.002 & -.47 & $f_{3}$ & .002 & .56 & $k 3$ & .006 & 1.52 \\
\hline $\mathrm{c}_{4}$ & -.006 & -1.38 & $f_{4}$ & -.003 & -.78 & $k 4$ & .000 & .01 \\
\hline $\mathrm{c}_{5}$ & -.003 & $-\quad .84$ & $f_{5}$ & .004 & .97 & $k 5$ & .005 & 1.20 \\
\hline \multicolumn{9}{|c|}{ Panel B: NASDAQ Stocks } \\
\hline & Coeff. & T-ratio & \multicolumn{2}{|c|}{ Coeff. } & T-ratio & & Coeff & T-ratio \\
\hline$\overline{a_{1}}$ & -.023 & -5.75 & $\mathrm{~d}_{1}$ & .049 & 12.70 & $g_{1}$ & .091 & 23.28 \\
\hline$a_{2}$ & -022 & -5.39 & $\mathrm{~d}_{2}$ & .022 & 5.85 & $g_{2}$ & .043 & 11.20 \\
\hline$a_{3}$ & -.041 & -9.97 & $\mathrm{~d}_{3}$ & .015 & 3.83 & $g_{3}$ & .017 & 4.32 \\
\hline$a_{4}$ & -.021 & -5.10 & $\mathrm{~d}_{4}$ & .010 & 2.71 & $g_{4}$ & .013 & 3.30 \\
\hline$a_{5}$ & -.017 & -4.33 & $\mathrm{~d}_{5}$ & .000 & .04 & $g_{5}$ & .004 & 1.06 \\
\hline$b_{0}$ & .093 & 23.74 & & & & & & \\
\hline$b_{1}$ & .001 & .20 & $\mathrm{e}_{1}$ & .209 & 55.18 & $h_{1}$ & -.231 & -64.50 \\
\hline$b_{2}$ & -.011 & -2.85 & $\mathrm{e}_{2}$ & .094 & 23.60 & $h_{2}$ & .048 & 12.78 \\
\hline$b_{3}$ & -.007 & -1.82 & $\mathrm{e}_{3}$ & .039 & 9.83 & $h_{3}$ & .039 & 10.37 \\
\hline$b_{4}$ & -.011 & -2.69 & $\mathrm{e}_{4}$ & .025 & 6.32 & $h_{4}$ & .021 & 5.52 \\
\hline$b_{5}$ & -.008 & -2.18 & $\mathrm{e}_{5}$ & .019 & 4.90 & $h_{5}$ & .012 & 3.38 \\
\hline$c_{1}$ & -.010 & -2.26 & $f_{1}$ & .031 & 7.61 & $k 1$ & .029 & 8.04 \\
\hline $\mathrm{c}_{2}$ & -.012 & -2.72 & $f_{2}$ & .007 & 1.58 & $k 2$ & .004 & 1.10 \\
\hline$c_{3}$ & .001 & -.14 & $f_{3}$ & .008 & 1.88 & $k 3$ & .000 & .01 \\
\hline $\mathrm{c}_{4}$ & .014 & 3.32 & $f_{4}$ & .002 & .42 & $k 4$ & -.002 & -.54 \\
\hline $\mathrm{c}_{5}$ & .002 & .49 & $f_{5}$ & .003 & .71 & $k 5$ & .007 & 1.95 \\
\hline
\end{tabular}

Panel A: NYSE Stocks 
Table 5

\section{The Day-of-the-week and the Time-of-the-day Effects}

The Model is:

$$
\begin{aligned}
& r_{t}=\sum_{i=1}^{5} a_{i} r_{t-i}+\sum_{i=0}^{5} b_{i} x_{t-i}+\sum_{i=1}^{5} c_{i} z_{t-i}+\sum_{k=1}^{5} \phi_{k} D_{k t}+\sum_{j=1}^{3} \gamma_{j} I_{j t}+\varepsilon_{t} ; \\
& x_{t}=\sum_{i=1}^{5} d_{i} x_{t-i}+\sum_{i=1}^{5} e_{i} r_{t-i}+\sum_{i=1}^{5} f_{i} z_{t-i}+\sum_{k=1}^{5} \varphi_{k} D_{k t}+\sum_{j=1}^{3} \lambda_{j} I_{j t}+\eta_{t} ; \\
& z_{t}=\sum_{i=1}^{5} g_{i} z_{t-i}+\sum_{i=1}^{5} h_{i} r_{t-i}+\sum_{i=1}^{5} k_{i} x_{t-i}+\sum_{k=1}^{5} \tau_{k} D_{k t}+\sum_{j=1}^{3} \psi_{j} I_{j t}+\zeta_{t} ;
\end{aligned}
$$

where $r_{t}$ is the quote-return at time $\mathrm{t}$ and $x_{t}$ is the net-buy volume at time $\mathrm{t}, D_{k t}$ 's are the day-ofthe-week dummy variables and $I_{j t}$ 's are the dummy variables to capture time-of-the-day effects. $I_{1 t}$ is equal to 1 during 9:30 a.m. to 10:30 a.m. (opening hour), $I_{2 t}$ is equal to 1 during 12:30 p.m.

\begin{tabular}{|c|c|c|c|c|c|c|}
\hline & Coeff. & T-ratio & Coeff. & T-ratio & Coeff. & T-ratio \\
\hline & \multicolumn{2}{|c|}{ Quote-Return } & \multicolumn{2}{|c|}{ Net-Buy Volume } & \multicolumn{2}{|c|}{$\underline{\text { Net-Depth }}$} \\
\hline Monday & .005 & .59 & -.011 & -1.28 & -.014 & -1.53 \\
\hline Tuesday & -.002 & -.27 & -.005 & -.59 & -.012 & -1.46 \\
\hline Wednesday & .006 & .72 & -.001 & -.06 & -.012 & -1.40 \\
\hline Thursday & .011 & 1.34 & -.001 & -. 03 & -.013 & -1.56 \\
\hline Friday & .004 & .52 & -.007 & -.80 & -.014 & -1.64 \\
\hline Opening $\mathrm{Hr}$ & -.031 & -2.35 & .010 & .77 & .014 & 1.10 \\
\hline Mid-day & .021 & 2.18 & .004 & .43 & .002 & .21 \\
\hline Closing $\mathrm{Hr}$ & .006 & .64 & .003 & .35 & .069 & 7.11 \\
\hline
\end{tabular}
to 1:30 p.m. (mid-day), and $I_{3 t}$ is equal to 1 during 3:00 p.m. to 4:00 p.m. (closing hour).

Panel A: NYSE Stocks

Panel B: NASDAQ Stocks

\begin{tabular}{lcclccr}
\hline & Coeff. & T-ratio & Coeff. & T-ratio & Coeff. & T-ratio \\
\cline { 3 - 4 } & \multicolumn{2}{c}{ Quote-Return } & & Net-Buy Volume & & \multicolumn{2}{r}{ Net-Depth } \\
Monday & .004 & .45 & -.030 & -3.43 & .021 & 2.62 \\
Tuesday & .002 & .19 & -.022 & -2.74 & .015 & 1.97 \\
Wednesday & -.003 & -.36 & -.018 & -2.17 & .006 & .78 \\
Thursday & .004 & .47 & -.015 & -1.80 & .013 & 1.77 \\
Friday & -.005 & -.54 & -.030 & -3.60 & .003 & .43 \\
Opening Hr & -.046 & -3.51 & .066 & 5.15 & -.070 & -5.80 \\
Mid-day & .026 & 2.76 & -.040 & -4.16 & -.008 & -.94 \\
Closing Hr & -.000 & -.01 & .062 & 6.65 & -.039 & -4.36
\end{tabular}




\section{Figure 2: Impulse Response Analysis of Walt Disney Company}

Panel A: January 10, 2000

\section{Return}

Response of RETURNDJ to One S.D. RETURNDJ Innovation

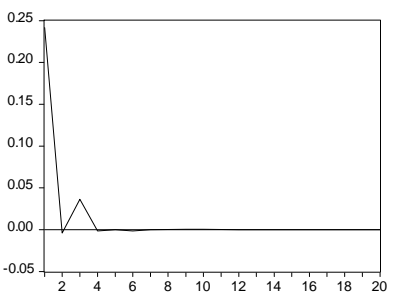

Response of VOLUMEDJ to One S.D. RETURNDJ Innovation

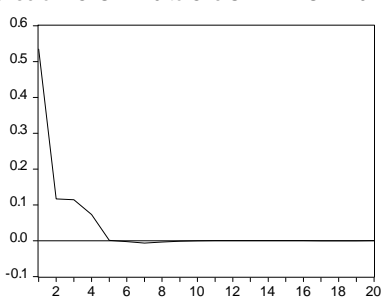

Response of DEPTHDJ to One S.D. RETURNDJ Innovation

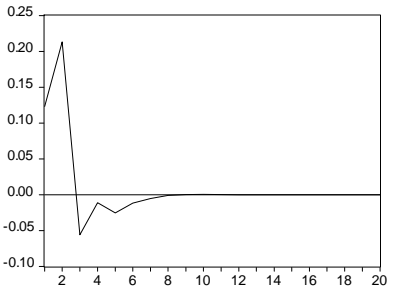

Volume

Response of RETURNDJ to One S.D. VOLUMEDJ Innovation

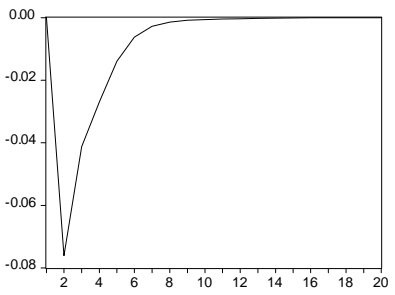

Response of VOLUMEDJ to One S.D. VOLUMEDJ Innovation

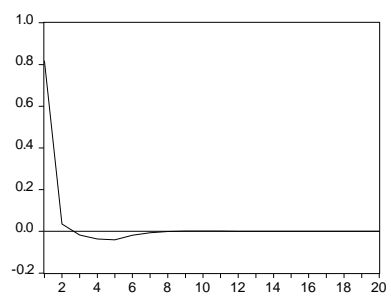

Response of DEPTHDJ to One S.D. VOLUMEDJ Innovation

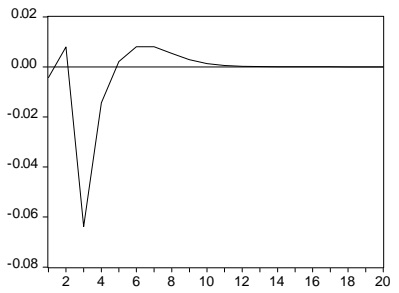

Depth

Response of RETURNDJ to One S.D. DEPTHDJ Innovation

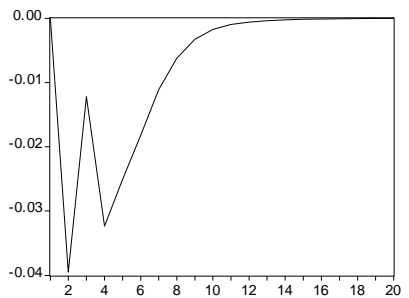

Response of VOLUMEDJ to One S.D. DEPTHDJ Innovation

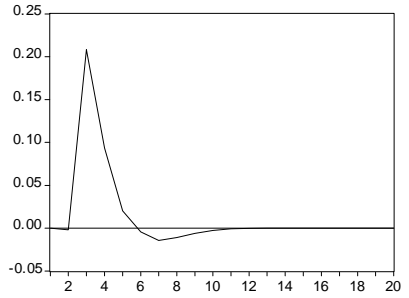

Response of DEPTHDJ to One S.D. DEPTHDJ Innovation

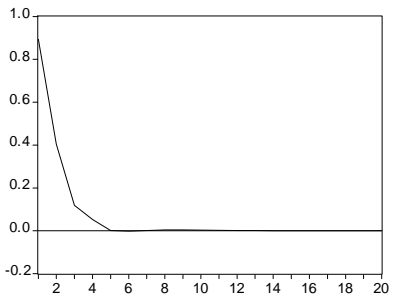


Panel B: January 11, 2000

\section{Return}

Response of RETURNDJ to One S.D. RETURNDJ Innovation

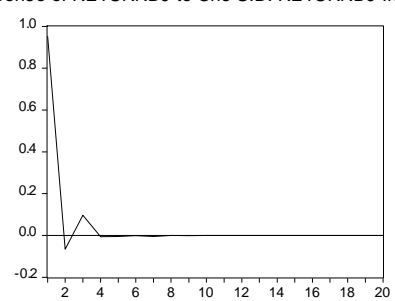

Response of VOLUMEDJ to One S.D. RETURNDJ Innovation

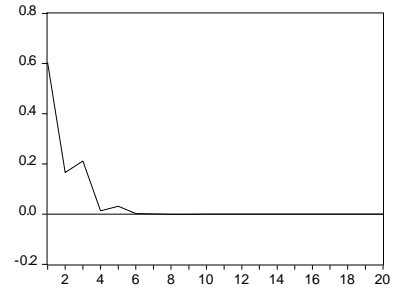

Response of DEPTHDJ to One S.D. RETURNDJ Innovation

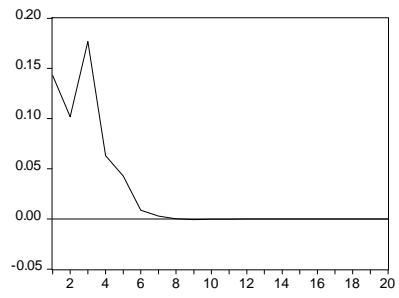

Volume

Response of RETURNDJ to One S.D. VOLUMEDJ Innovation

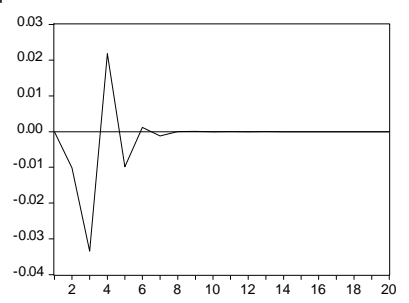

Response of VOLUMEDJ to One S.D. VOLUMEDJ Innovation

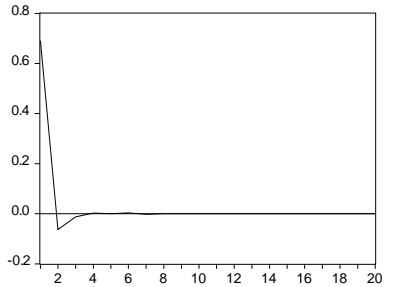

Response of DEPTHDJ to One S.D. VOLUMEDJ Innovation

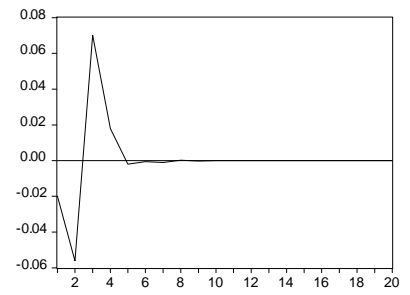

Depth

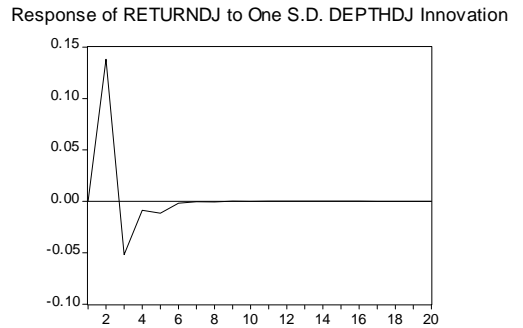

Response of VOLUMEDJ to One S.D. DEPTHDJ Innovation

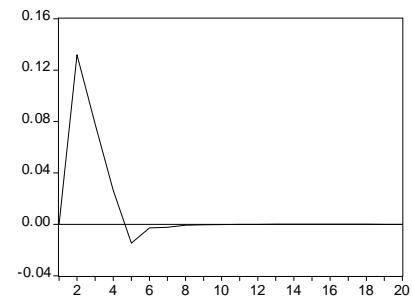

Response of DEPTHDJ to One S.D. DEPTHDJ Innovation

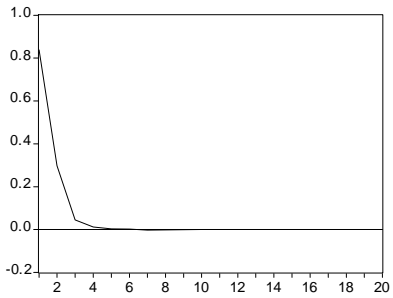


Panel C: January 12, 2000

Return

Volume

Response of RETURNDJ to One S.D. RETURNDJ Innovation Response of RETURNDJ to One S.D. VOLUMEDJ Innovation
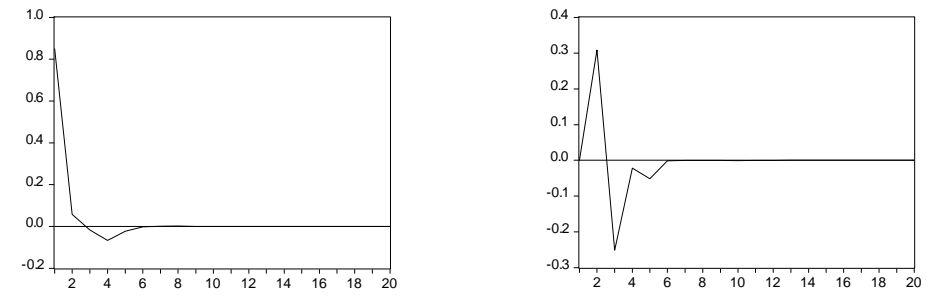

Response of VOLUMEDJ to One S.D. RETURNDJ Innovation Response of VOLUMEDJ to One S.D. VOLUMEDJ Innovation

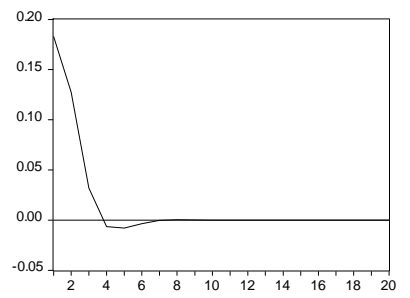

Response of DEPTHDJ to One S.D. RETURNDJ Innovation

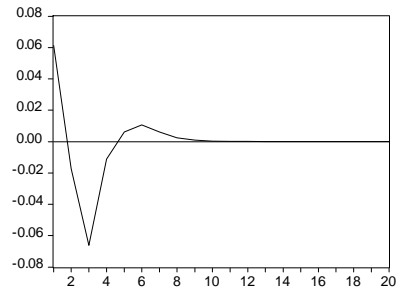

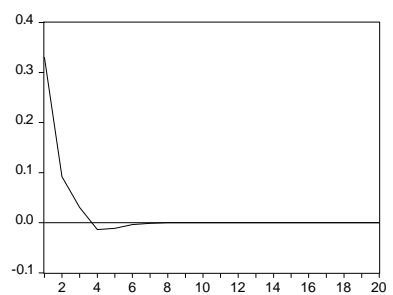

Response of DEPTHDJ to One S.D. VOLUMEDJ Innovation

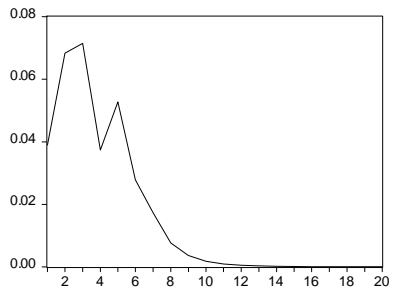

\section{Depth}

Response of RETURNDJ to One S.D. DEPTHDJ Innovation

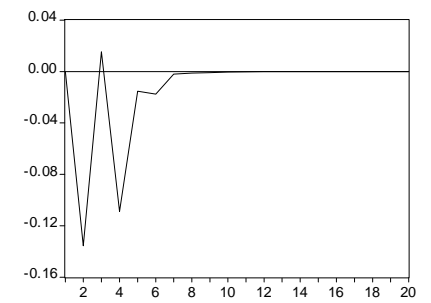

Response of VOLUMEDJ to One S.D. DEPTHDJ Innovation

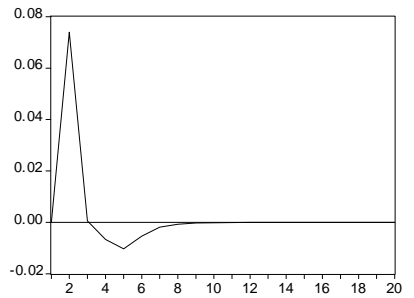

Response of DEPTHDJ to One S.D. DEPTHDJ Innovation

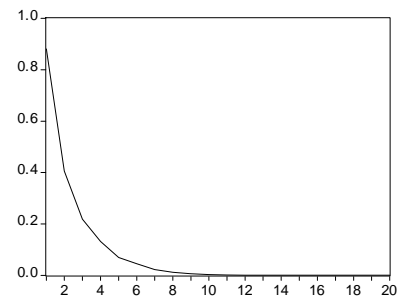


Figure 3: Impulse Response Analysis of Dell Computers

Panel A: March 10, 2000

Return

Response to One S.D. Innovations

Response of RETURNN to RETURNN

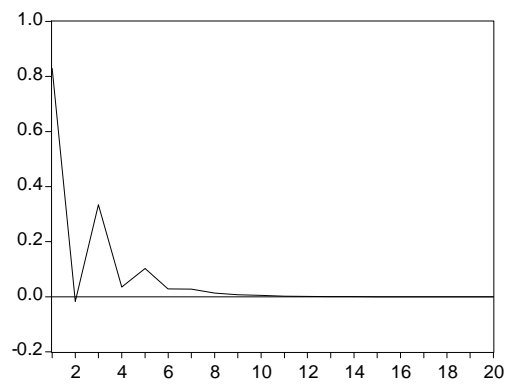

Response of VOLUMEN to RETURNN

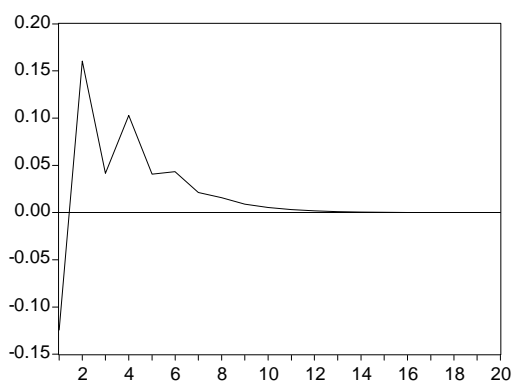

Response of DEPTHN to RETURNN

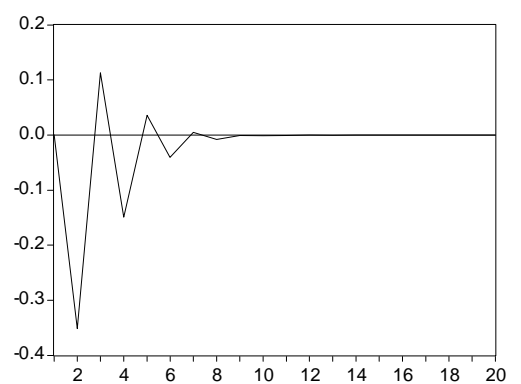

Volume

Response to One S.D. Innovations

Response of RETURNN to VOLUMEN

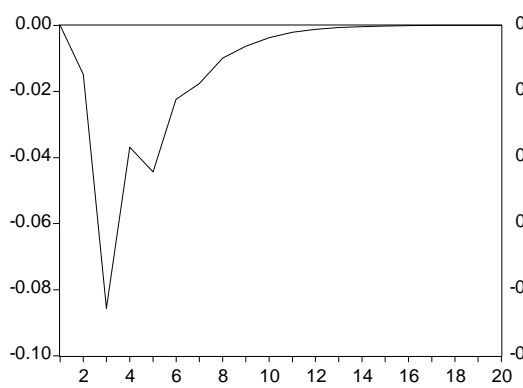

Response of VOLUMEN to VOLUMEN

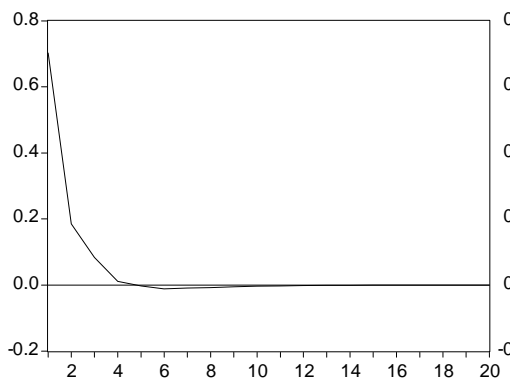

Response of DEPTHN to VOLUMEN

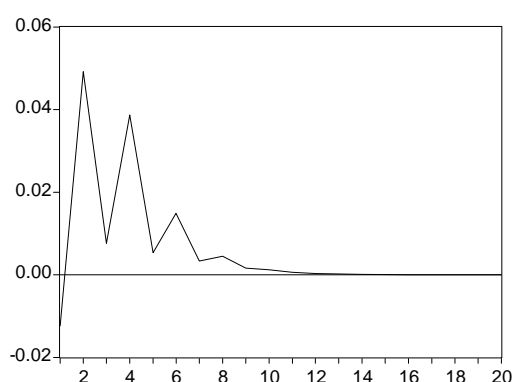

Depth

Response to One S.D. Innovations

Response of RETURNN to DEPTHN

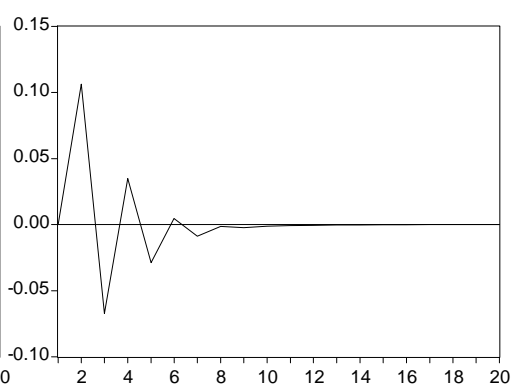

Response of VOLUMEN to DEPTHN

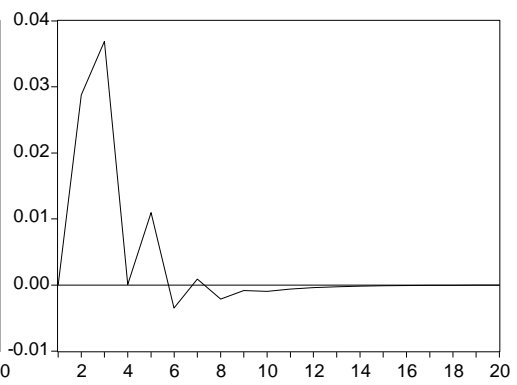

Response of DEPTHN to DEPTHN

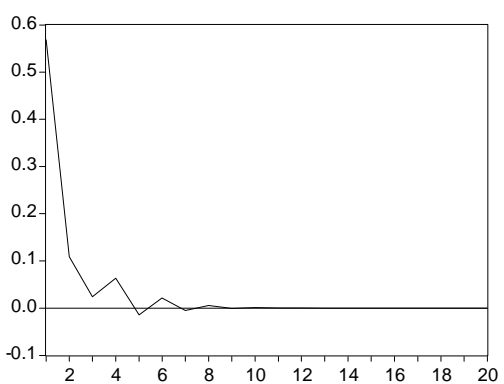


Panel B: March 13, 2000

Return

Response to One S.D. Innovations

Response of RETURNN to RETURNN

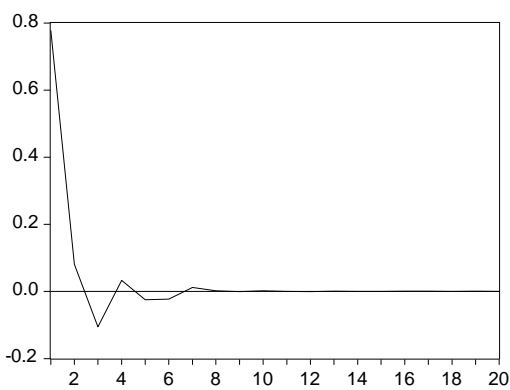

Response of VOLUMEN to RETURNN

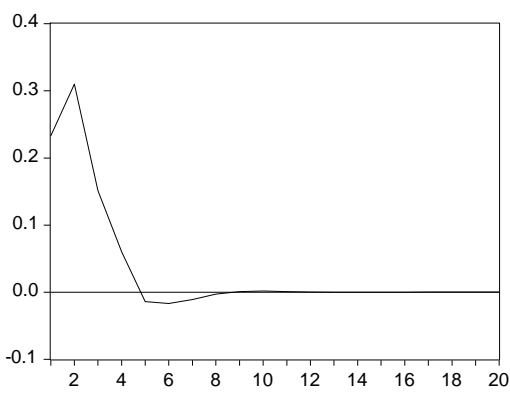

Response of DEPTHN to RETURNN

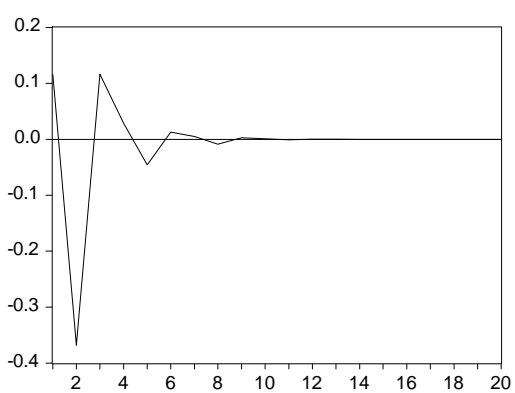

Volume

Response to One S.D. Innovations

Response of RETURNN to VOLUMEN

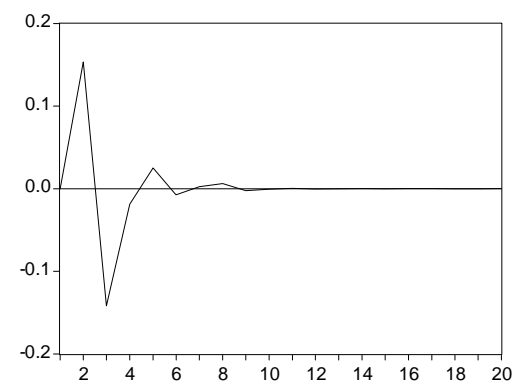

Response of VOLUMEN to VOLUMEN

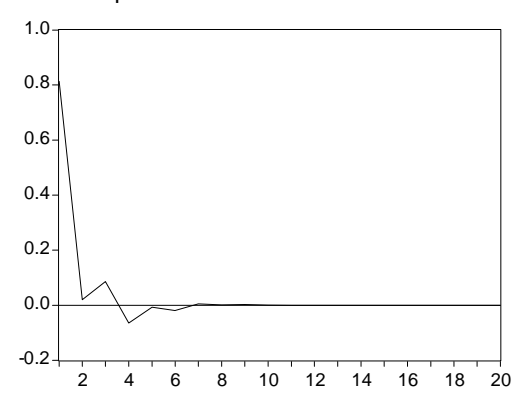

Response of DEPTHN to VOLUMEN

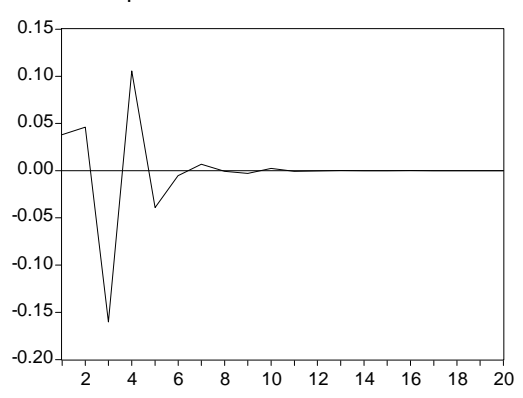

Depth

Response to One S.D. Innovations

Response of RETURNN to DEPTHN

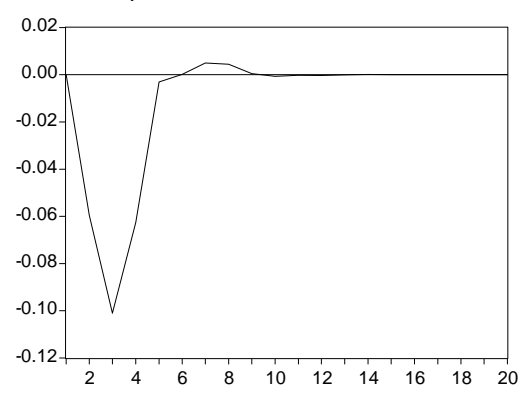

Response of VOLUMEN to DEPTHN

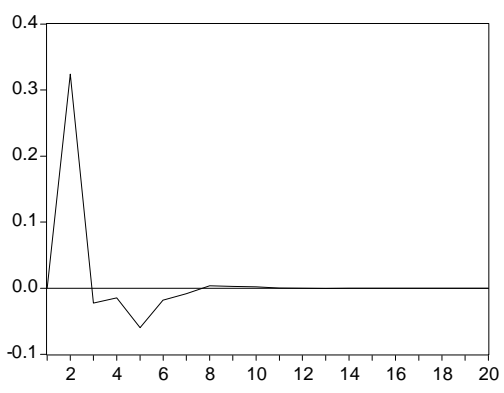

Response of DEPTHN to DEPTHN

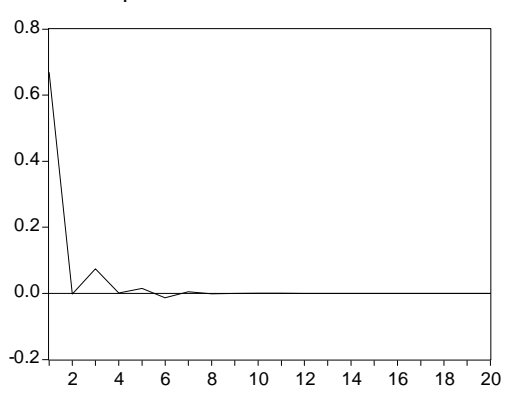


Panel C: March 14, 2000

Return

Response to One S.D. Innovations

Response of RETURNN to RETURNN

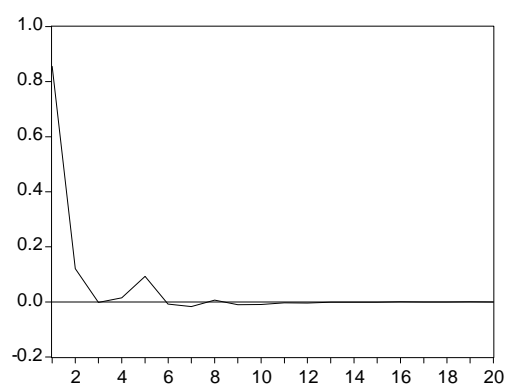

Response of VOLUMEN to RETURNN

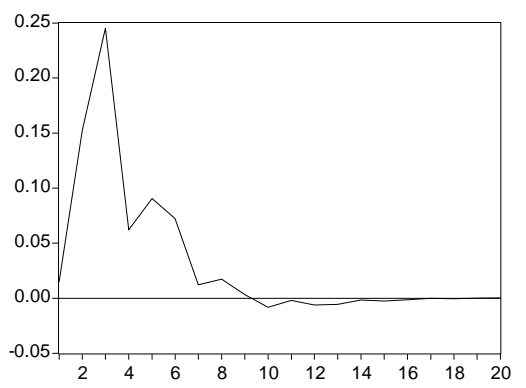

Response of DEPTHN to RETURNN

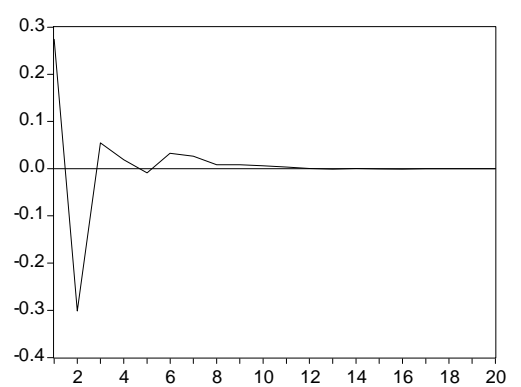

Volume

Response to One S.D. Innovations

Response of RETURNN to VOLUMEN

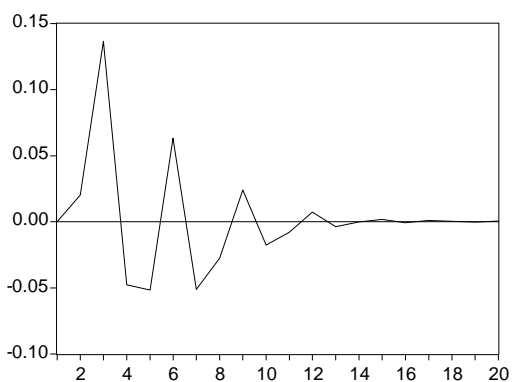

Response of VOLUMEN to VOLUMEN

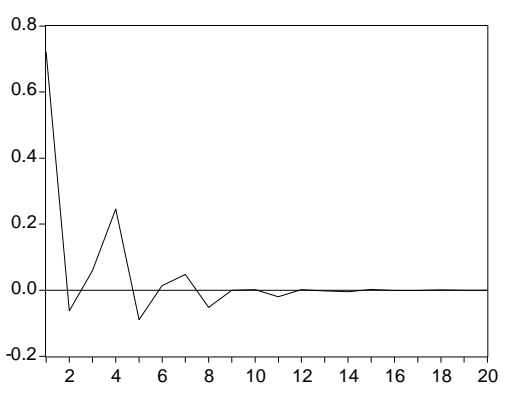

Response of DEPTHN to VOLUMEN

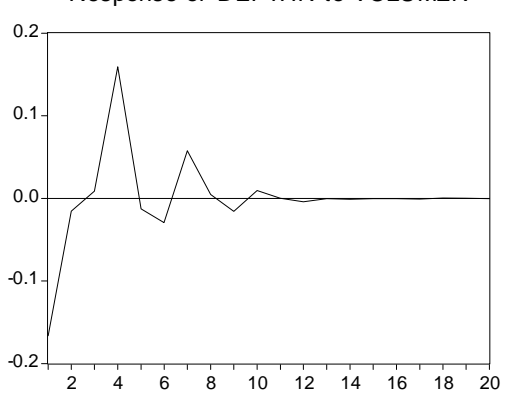

Depth

Response to One S.D. Innovations

Response of RETURNN to DEPTHN

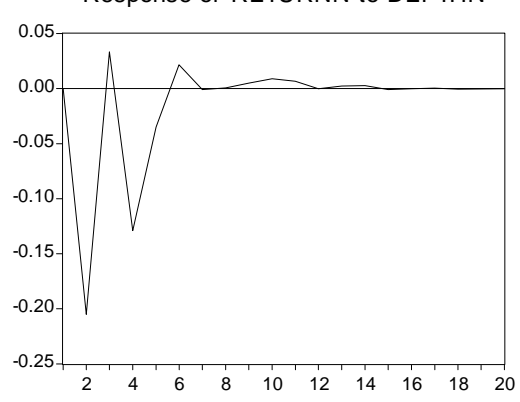

Response of VOLUMEN to DEPTHN

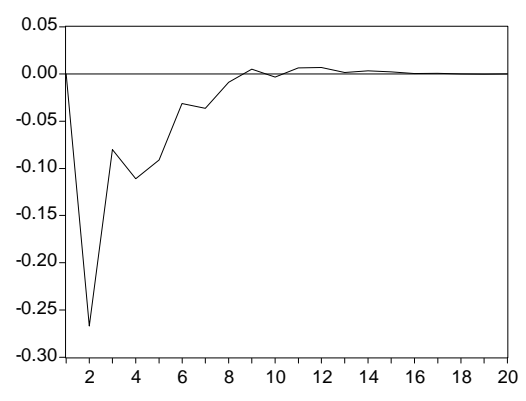

Response of DEPTHN to DEPTHN

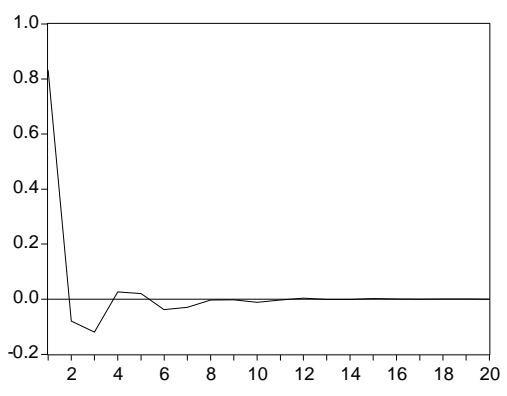


Figure 4: Impulse Response Analysis of Microsoft

Panel A: March 23, 2000

Return

Response to One S.D. Innovations

Response of RETURNN to RETURNN

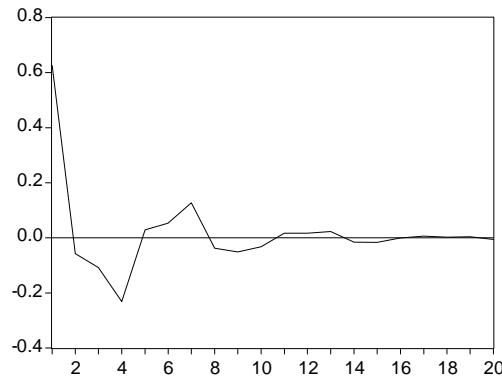

Response of VOLUMEN to RETURNN

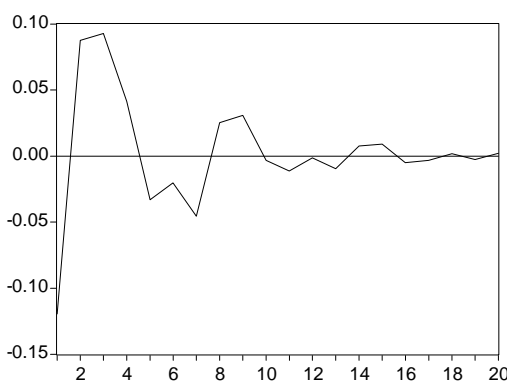

Response of DEPTHN to RETURNN

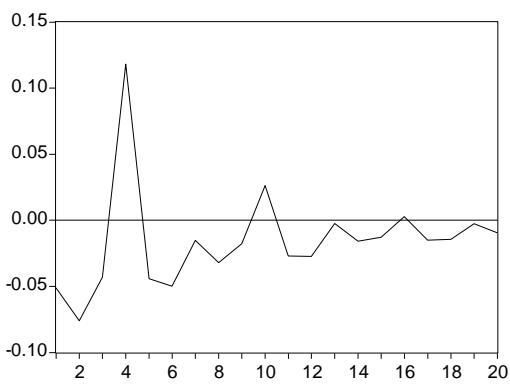

Volume

Response to One S.D. Innovations

Response of RETURNN to VOLUMEN

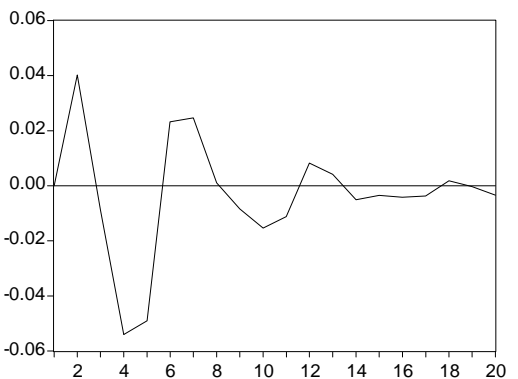

Response of VOLUMEN to VOLUMEN

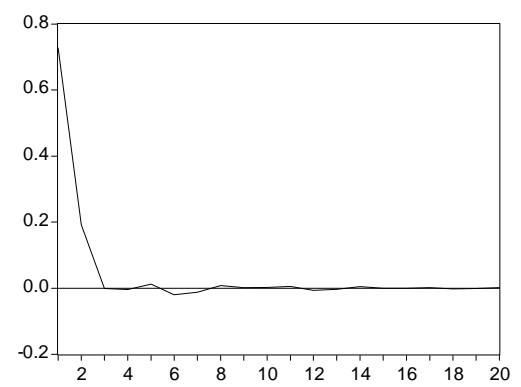

Response of DEPTHN to VOLUMEN

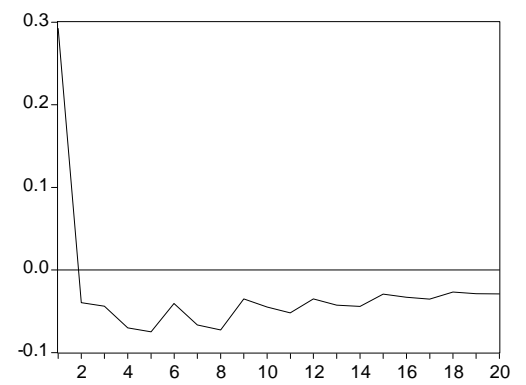

Depth

Response to One S.D. Innovations

Response of RETURNN to DEPTHN

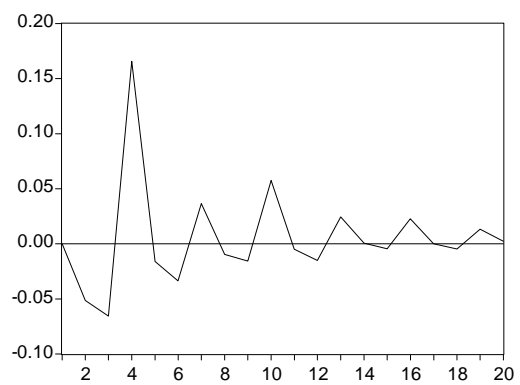

Response of VOLUMEN to DEPTHN

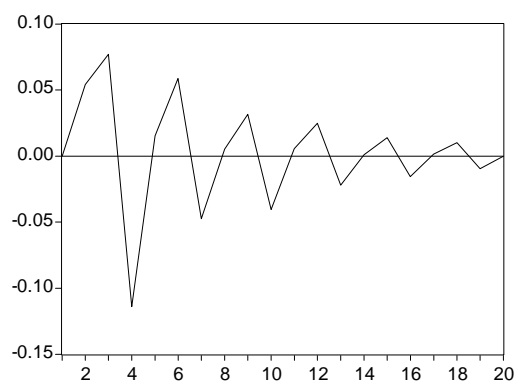

Response of DEPTHN to DEPTHN

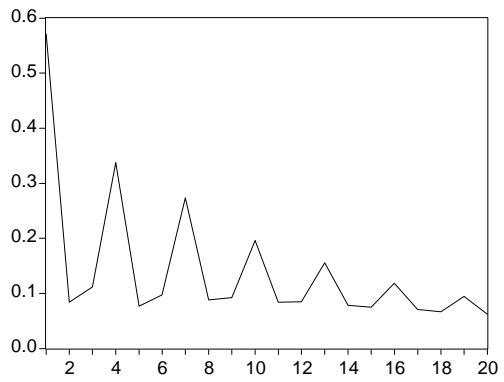


Panel B: March 24, 2000

\section{Return}

Response to One S.D. Innovations

Response of RETURNN to RETURNN

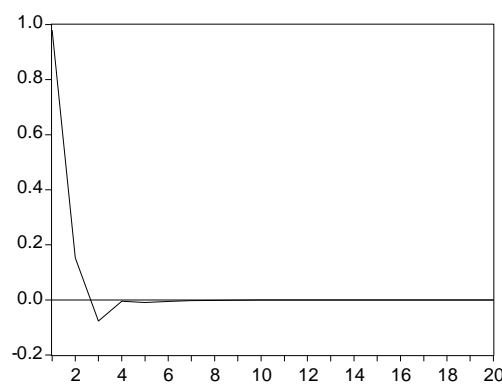

Response of VOLUMEN to RETURNN

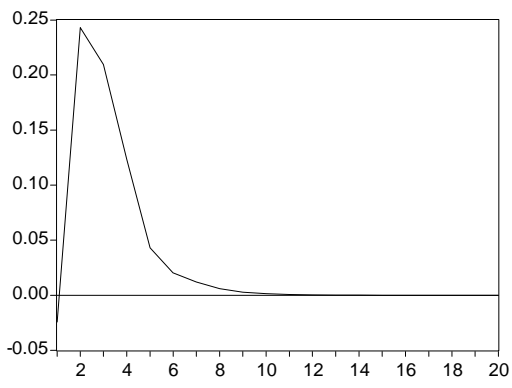

Response of DEPTHN to RETURNN

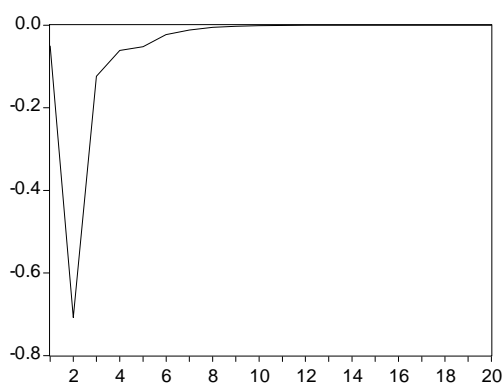

Volume

Response to One S.D. Innovations

Response of RETURNN to VOLUMEN

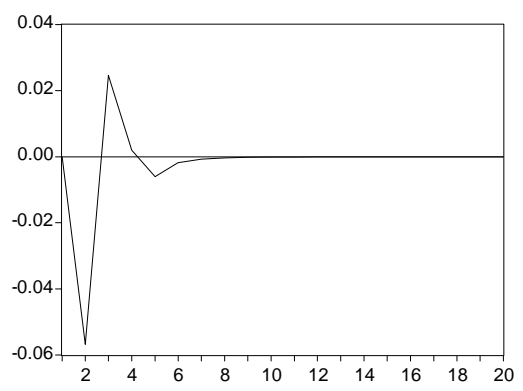

Response of VOLUMEN to VOLUMEN

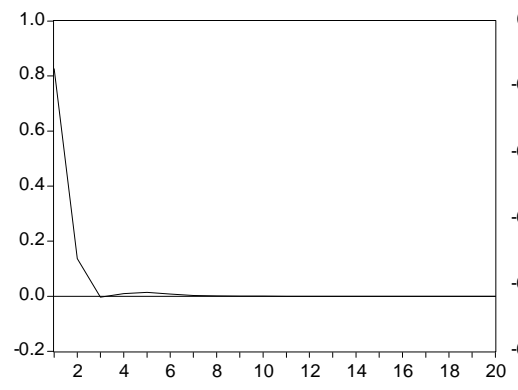

Response of DEPTHN to VOLUMEN

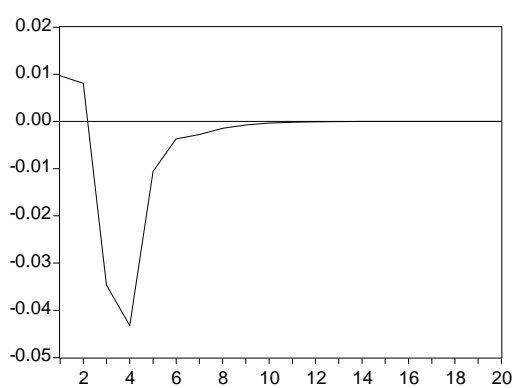

Depth

Response to One S.D. Innovations

Response of RETURNN to DEPTHN

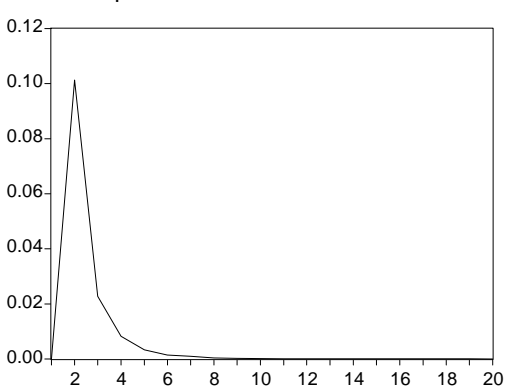

Response of VOLUMEN to DEPTHN

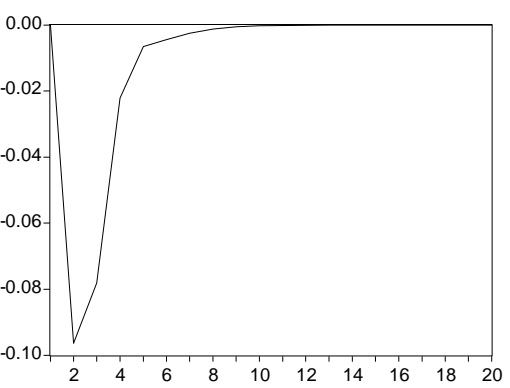

Response of DEPTHN to DEPTHN

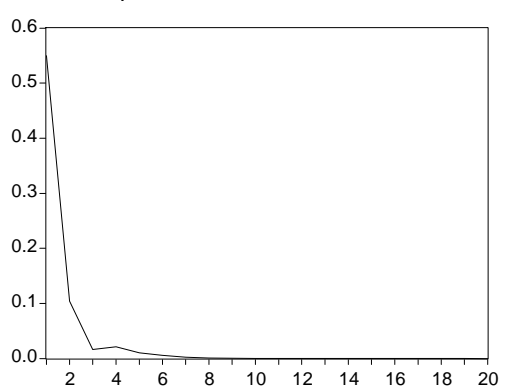


Panel C: March 27, 2000

Return

Response to One S.D. Innovations

Response of RETURNN to RETURNN

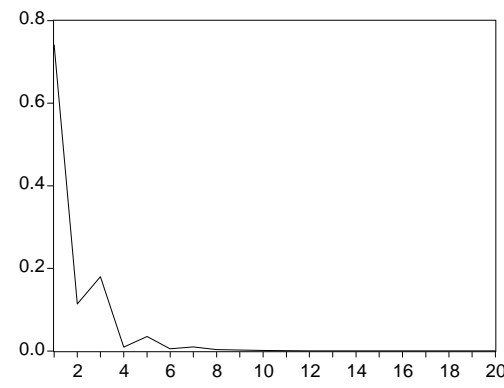

Response of VOLUMEN to RETURNN

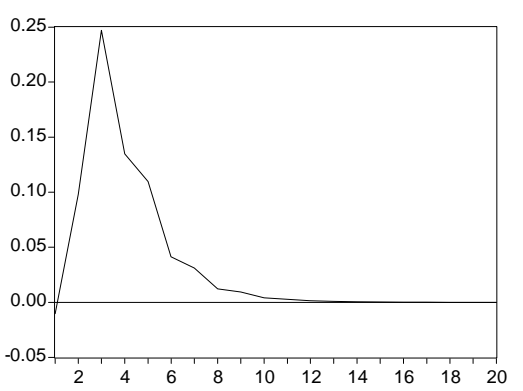

Response of DEPTHN to RETURNN

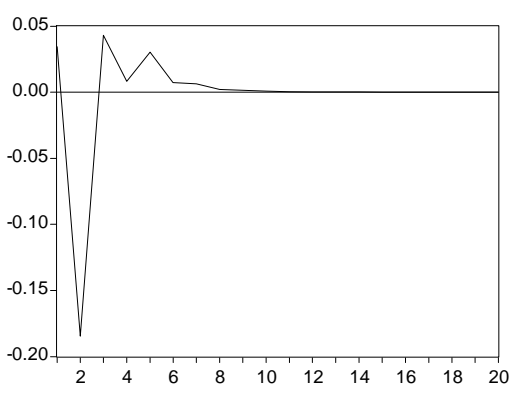

Volume

Depth

Response to One S.D. Innovations

Response of RETURNN to VOLUMEN

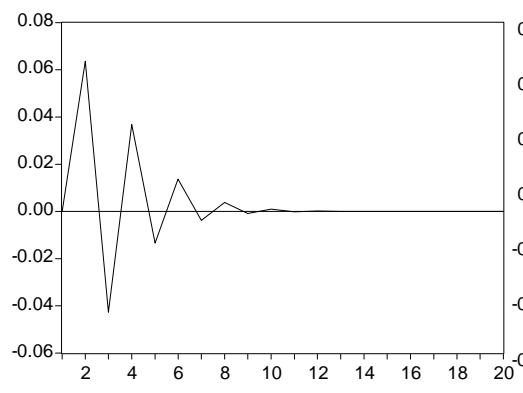

Response to One S.D. Innovations

Response of RETURNN to DEPTHN

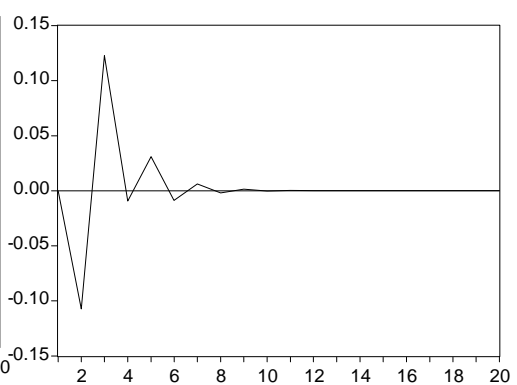

Response of VOLUMEN to VOLUMEN

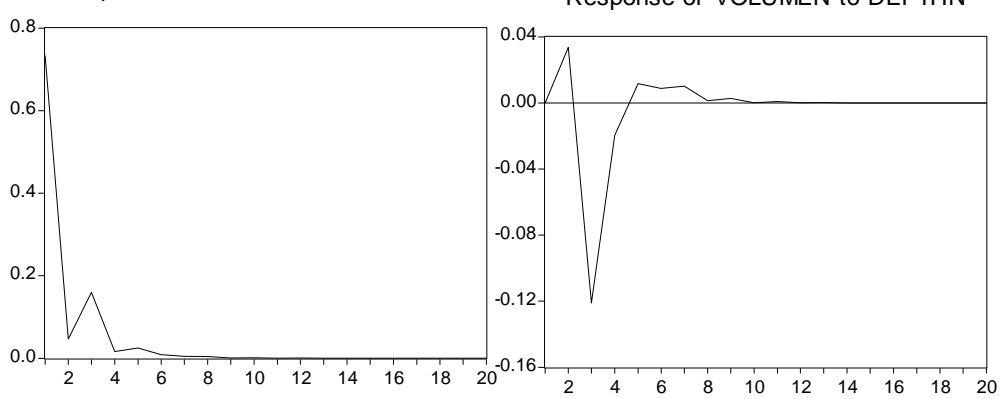

Response of DEPTHN to VOLUMEN

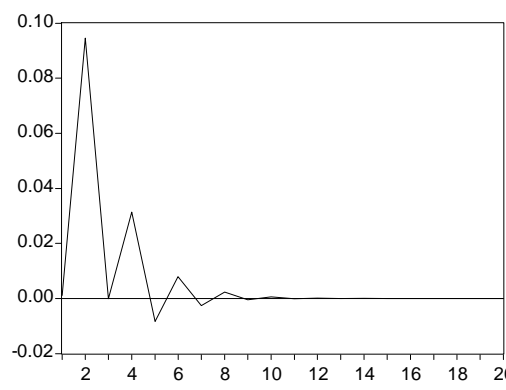

Response of DEPTHN to DEPTHN

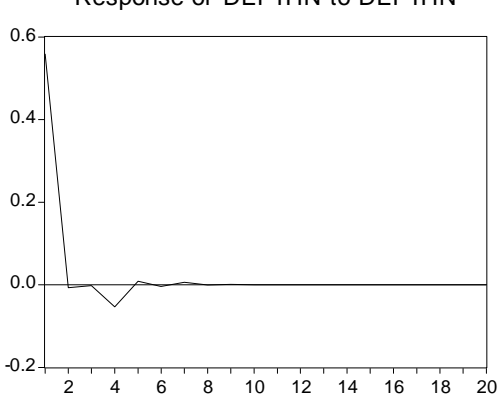




\section{Figure 5: Impulse Response Analysis of Wal-Mart Corporation}

Panel A: March 29, 2000

Return

Volume

Depth
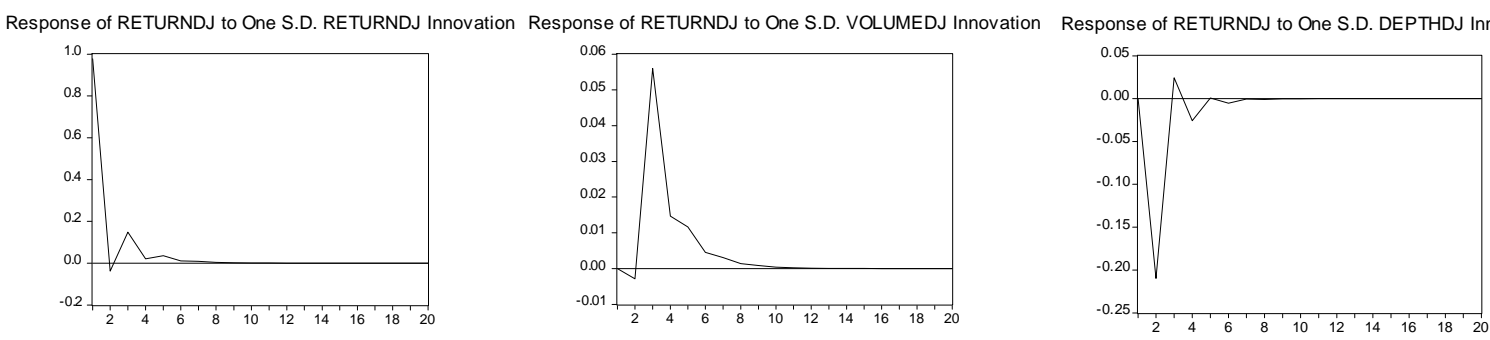

Response of VOLUMEDJ to One S.D. RETURNDJ Innovation Response of VOLUMEDJ to One S.D. VOLUMEDJ Innovation
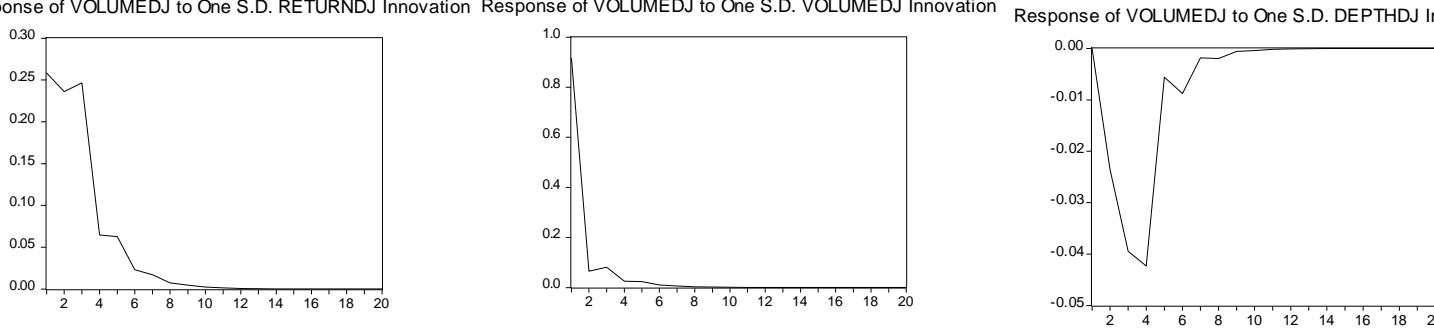

Response of DEPTHDJ to One S.D. RETURNDJ Innovation

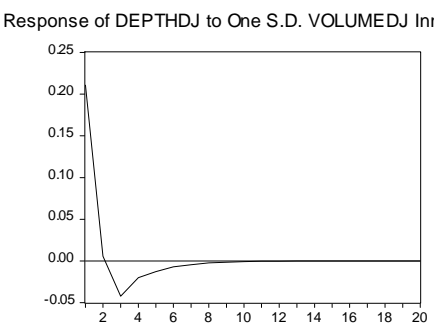

Response of DEPTHDJ to One S.D. DEPTHDJ Innovation
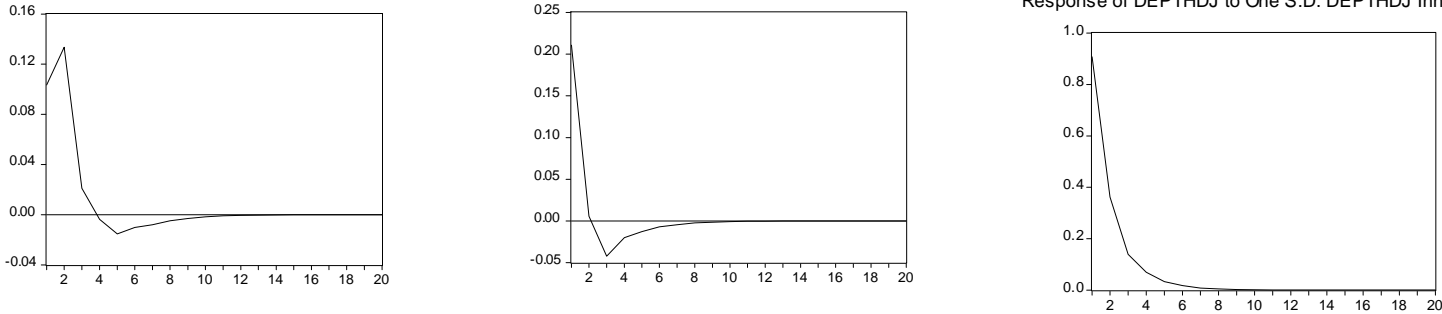


\section{Panel B: March 30, 2000}

Return

Response of RETURNDJ to One S.D. RETURNDJ Innovation

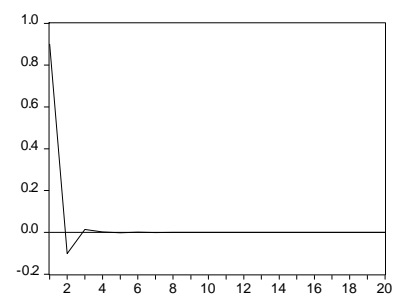

Response of VOLUMEDJ to One S.D. RETURNDJ Innovation

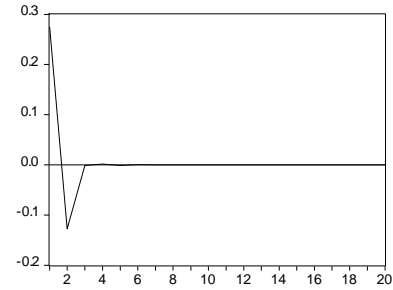

Response of DEPTHDJ to One S.D. RETURNDJ Innovation

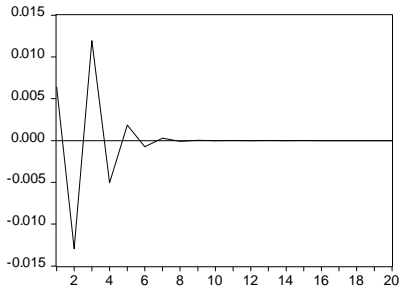

Volume

Depth
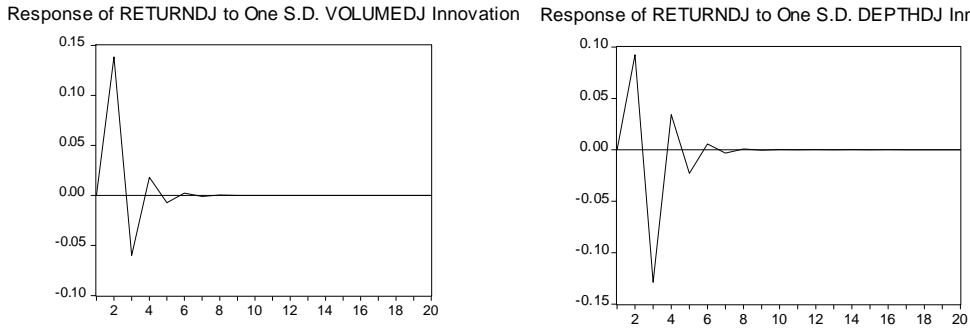

Response of VOLUMEDJ to One S.D. VOLUMEDJ Innovation

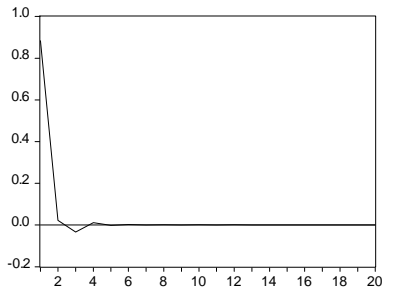

Response of VOLUMEDJ to One S.D. DEPTHDJ Innovation

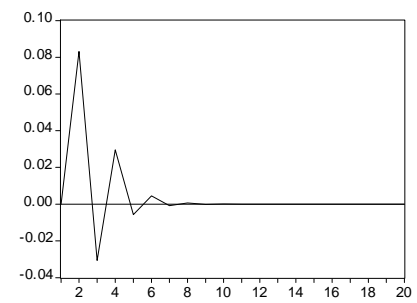

Response of DEPTHDJ to One S.D. VOLUMEDJ Innovation

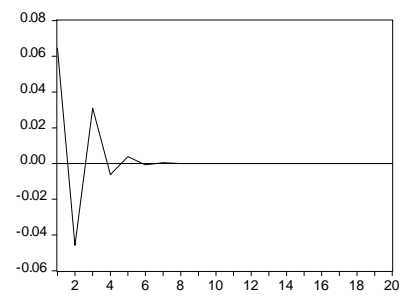

Response of DEPTHDJ to One S.D. DEPTHDJ Innovation

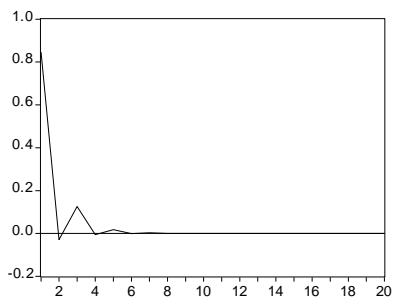

